Is Fuel-Switching a No-Regrets Environmental Policy?

VAR Evidence on Carbon Dioxide Emissions, Energy Consumption and Economic Performance in Portugal

\author{
Alfredo M. Pereira \\ College of William and Mary
}

Rui Manuel Marvão Pereira

Thomas Jefferson Program in Public Policy

College of William and Mary

Department of Economics

Working Paper Number 87

August 2009 
COLLEGE OF WILLIAM AND MARY

DEPARTMENT OF ECONOMICS

WORKING PAPER \# 87

August 2009

\title{
Is Fuel-Switching a No-Regrets Environmental Policy? VAR Evidence on Carbon Dioxide Emissions, Energy Consumption and Economic Performance in Portugal
}

\begin{abstract}
The objective of this paper is to estimate the impact of carbon dioxide emissions from fossil fuel combustion activities on economic activity in Portugal in order to evaluate the economic costs of policies designed to reduce carbon dioxide emissions. We find that energy consumption has a significant impact on macroeconomic activity. In fact, a one ton of oil equivalent permanent reduction in aggregate energy consumption reduces output by €6,340 over the long term, an aggregate impact which hides a wide diversity of effects for different fuel types. More importantly, and since carbon dioxide emissions are linearly related to the amounts of fuel consumed, our results allow us to estimate the costs of reductions in carbon dioxide emissions from different energy sources. We estimate that marginal abatement costs for carbon dioxide are $€ 45.62$ per ton of carbon dioxide per year for coal, €66.52 for oil, €91.07 for gas, €191.13 for electricity and $€ 254.23$ for biomass. An important policy implication is that, once the overall economic costs of reducing carbon dioxide emissions are considered, fuel switching is a noregrets environmental policy capable of reducing carbon dioxide emissions without jeopardizing economic activity and indeed with the potential for generating favorable economic outcomes.
\end{abstract}

JEL Codes: C32, O13, Q43

Keywords: carbon dioxide emissions, energy and the economy, environmental policy, fuelswitching, vector autoregressive model

\author{
Alfredo Marvão Pereira \\ Department of Economics \\ College of William and Mary \\ Williamsburg, VA 23187-8795 \\ ampere@wm.edu
}

Rui Manuel Marvão Pereira

Thomas Jefferson Program in Public Policy

College of William and Mary

Williamsburg, VA 23187

rmpereira@wm.edu 


\section{Introduction}

The objective of this paper is to estimate the economic impact of carbon dioxide emissions from fossil fuel combustion activities in Portugal in order to evaluate the economic costs of policies to reduce carbon dioxide emissions. According to the Agência Portuguesa do Ambiente (2006a) (Portuguese Institute for the Environment, APA hereafter), carbon dioxide emissions from fossil fuel combustion in Portugal reached 56.950 $\mathrm{Mt} \mathrm{CO}_{2}$ in 2006. For the period 1990-2006 they account for $96.2 \%$ of total greenhouse gas emissions in the energy sector - the remainder being methane and nitrogen oxide emissions - and for $68.5 \%$ of total greenhouse gas emissions - the remainder being due to industrial processes, fugitive emissions from fuels, solvent and other product use, agriculture, and waste.

Environmental policies to reduce carbon dioxide emissions from fossil fuel combustion have traditionally focused on investment in research, development, and deployment of energy-efficient technologies, on restructuring the composition of fuel demand, and on reducing energy consumption. Naturally, the choice and design of such policies is bound to have an important impact on economic activity [see, for example, Manne and Richels (1992), Nordhaus (1993), Grubb et al. (1993), Gaskins and Weyant (1993), Zhang and Folmer (1998), Jorgenson (1998), Hue and Xu (2000) and Lasky (2003)]. Furthermore, not all policy alternatives are equally feasible in general and much more so in the case of a small economy like Portugal.

Energy-efficiency improvements have the potential for bringing significant gains in productivity while reducing the consumption of fossil fuels and greenhouse gas emissions [see, for example, Barker, et al. (2007) and Scott et al. (2008)]. Nevertheless, their scope 
is rather limited. The development of energy-efficient technologies is more of a longterm prospect and more outside the scope of small or developing economies. In turn, international studies have often concluded that the fuel switching necessary to ensure deep cuts in emissions would increase direct energy system costs for households and firms as a result of a regulatory-induced shift to more expensive but cleaner fuels. Accordingly, private incentives have done little to encourage the deployment of lowcarbon fuels. Finally, reducing energy consumption seems undesirable as, if taken literally, would adversely affect economic performance. Ultimately, these considerations highlight the perceived trade-off between reducing carbon dioxide emissions from fossil fuel combustion activities and economic performance [see, for example, Chen et al. (2005)] and the fact that policy instruments that promote fuel switching tend to be the policies of choice.

The objective of this paper is to contribute to the design of environmental policy instruments, and particularly, fuel-switching policies, which minimize the aggregate economic costs of regulation while effectively reducing emissions. Accordingly, we put aside the focus on private direct energy system costs to explore instead the impact of energy consumption on aggregate economic performance.

We start by considering the impact on aggregate output of final energy demand by type. Then, since carbon dioxide emissions are linearly related to the amounts of fuel consumed, our estimates of the impact of energy consumption on output allow us to estimate the marginal abatement costs for carbon dioxide emissions from fossil fuel combustion by energy source. This, in turn, allows us to gain an appreciation of the macroeconomic costs of policies directed at specific emission sources. 
We obtain the impact of energy demand on aggregate output by estimating a series of four-equation vector auto-regressive (VAR) models relating output, employment, private investment and either aggregate energy demand or disaggregate energy demand for different types of energy. This allows us to highlight the dynamic feedback mechanisms among the different variables and captures both direct and indirect channels through which energy consumption affects aggregate output as suggested by a production technology mapping labor, capital and energy consumption to output. On one hand, as an input to production, energy directly affects output - a scale effect. On the other hand, energy may affect production indirectly through its impact on other inputs - capital and labour - a substitution effect. Indeed, empirical evidence suggests that during periods of high energy prices, the tendency is for firms to switch to less energy-intensive capital equipment and for more labour-intensive industries to develop [see, for example, Jorgenson (1998)]. ${ }^{1}$

As a result, a VAR model is an ideal approach for estimating the impact of energy consumption on aggregate output. This is because by estimating four separate but simultaneous auto-regressive equations, we create a framework that allows us to estimate the effects of a change in energy demand resulting from an exogenous shock, such as climate change regulation, and follow the effects of this shock over time on output, employment, and private investment, which in turn feedback into energy demand itself. The final effect on output therefore measures both the direct scale effects on output of energy as a production input and the indirect substitution effects of energy on output as it

\footnotetext{
${ }^{1}$ The substitution of imported for domestic energy production is also, in general, an important element when measuring the output effects of changes in energy demand. In the Portuguese case, however, this is a rather marginal channel which is ignored in our analysis. In fact, Portugal has no recoverable non-renewable resources - no coal, oil or natural gas, while the demand for biomass is small. In turn, use of domestic renewable resources - wind, solar and hydropower, account for around one-fourth of electricity demand. Overall, in 2003, domestic sources accounted for no more than $12 \%$ of total final energy demand.
} 
affects the other inputs, employment and private investment, through time including in addition all the dynamic feedbacks from output and the other inputs into energy demand. ${ }^{2}$

Our methodological approach follows very much the recent trends in the literature. Recent advances in times-series analysis have stimulated research into the nature of the relationship between energy consumption and economic activity via the concept of Granger-causality [see, for example, Masih and Masih (1996), Cheng and Lai (1997), Asafu-Adjaye (2000), Stern (1993, 2000), and Oh and Lee (2004)]. Although the general results are mixed, the importance of the dynamic relationship between energy consumption and output is clear. In fact, bi-directional causality has served as the basis for generating forecasts of energy consumption based, at least partially, on the level of economic activity [see, for example, Crompton and Wu (2005), Francis et al. (2007), and Perobelli et al (2007)]. As a result, vector auto-regressive models have become a standard approach for forecasting energy consumption [see, for example, Energy Information Administration (2002)].

Our paper extends the literature to consider the impact of shocks to the demand for specific types of energy due to climate policy measures on output, employment and private investment. Climate policy induced reductions in energy consumption generate a series of responses in economic activity, which define the economic costs of regulation. As a result, we can consider not only the carbon content of the fuel when designing policies to reduce greenhouse gas emissions, but the impact of that source of energy on the economy as well. This allows us to prioritize policies that minimize the costs of

\footnotetext{
${ }^{2}$ We estimate a vector autoregressive model which is a system of four dynamic simultaneous equations for output, employment, private investment and energy demand. The autoregressive relationships among the equations within a particular system fully capture the direct and indirect effects and feedback mechanisms between energy demand and employment, private investment and output without need to resort to a two-step procedure.
} 
compliance with environmental regulation and better understand the economic costs of fuel switching policy measures.

\section{Data and Preliminary Empirical Results}

This section describes the basic data set, presents the results of the unit root and cointegration tests, and addresses the issue of VAR model specification.

\subsection{Data: sources and description}

We use annual data for output, employment, and private investment, as well as aggregate and disaggregated final demand for energy from 1977 to 2003, that is a 27-year period. Since this sample period includes years before and after Portugal joined the European Union in 1986, the possibility of a structural break in 1986 is considered throughout the empirical analysis - unit roots and co-integration tests as well as VAR specification and estimation.

Economic data was obtained from Banco de Portugal (1997), Commission of the European Communities (1999) and Ministério das Finanças (2006). Data for final demand for energy was obtained from the Energy Balance Sheets published by Direcção Geral de Energia (Portuguese Department of Energy, DGE hereafter) and is measured in $10^{3}$ tons of oil equivalent (toe hereafter). Aggregate final demand for energy is defined as the sum of final demand for petroleum and its derivatives, coal, gas, biomass, and electricity. See Table 1 for the evolution of the composition of the final energy demand.

Data for the final demand for energy products is compiled and published by the DGE. In 1990, the DGE changed its data collection methodology in order to better reflect the 
distinction between primary and final energy demand. As a result, the DGE makes available two data sets - one for the period between 1971 and 1993 and another for the period between 1990 and 2003 - with a four-year overlap. The data collection methodology and presentation differs between the two periods and in order to ensure consistency between the two series, several methodological issues are taken into consideration as will be mentioned below.

The data for petroleum and its derivatives includes liquefied petroleum gas, gasoline, diesel and fuel oil. Although the dominant use of petroleum and its derivates is as an energy source, they are also used as raw materials in the production of, for example, plastics and asphalt. Petroleum derivatives used as raw materials are not considered in our data, with the exception of fuel oil. This is because prior to 1985 the DGE accounting methodology did not distinguish between fuel oil used for energy and non-energy purposes. Petroleum and its derivatives account for an average of $66.3 \%$ of total final energy demand for the sample period and show a declining trend from $69.6 \%$ between 1977 and 1985 to $63.9 \%$ in the final years of the sample period.

The data on final demand for coal includes domestic production and imports of anthracite and bituminous coal. This data set is rather consistent methodologically throughout the sample period and therefore no adjustments to the published data were necessary. Coal constitutes $4.5 \%$ of total final energy demand for the sample period. Its weight in total final energy consumption has shown some fluctuations, starting at 3.9\% in the beginning of the sample period reaching a high of $6.0 \%$ for 1986 to 1997 and decreasing to $2.1 \%$ in the last five years of the sample period. The virtual extinction of the domestic coal mining industry - the last coal mine in Portugal producing primarily 
low grade anthracite closed in 1994 - largely contributed to the steady decline in coal consumption, particularly after 1986.

Data for gas includes coke gas, blast furnace gas, city gas and natural gas. Natural gas distribution infrastructure developed rapidly after 1998 to become an important component of the energy system. The demand for gas itself has increased significantly with the introduction of natural gas. In fact, the average share of gas in total final energy consumption for the period 1977-1985 was $1.2 \%$ and rose to 5.8\% between 1998 and 2003. Gas consumption grew, on average, at an average annual rate of $24.1 \%$ after the introduction of natural gas in 1998. In our empirical analysis below - unit roots and cointegration tests as well as VAR specification and estimation - we fully consider the possibility of a structural break in 1998 consistent with the introduction of natural gas.

Final demand for biomass includes registered purchases up until 1993, after which, data is based upon household surveys and thus reports both purchases and collection of biomass and forest waste. In order to generate a consistent series in levels, the growth rate of biomass consumption after 1993 is applied to the earlier level data. We find that the implied growth rate during the overlapping period 1990-1993 is consistent, albeit with relatively insignificant deviations. The use of biomass has decreased in relative importance over the sample period. Between 1977 and 1985, biomass consumption represents $8.7 \%$ of total final energy demand while in the final years of the sample period biomass consumption accounts for only $6.1 \%$ of total final energy demand.

Data for electricity consumption includes electricity as well as a residual component of cogeneration and heat until 1993, after which heat is accounted for separately and more thoroughly. For the overlapping years of 1990 - 93 the levels for the earlier series 
and the more recent series for electricity alone differ by an average of about $1 \%$ thus indicating that, indeed, cogeneration was just a marginal and residual component of the earlier series. Therefore, in order to generate a consistent series for electricity consumption in levels, we consider the level data available for 1977 - 93 and then simply apply the growth rates of electrical consumption after 1993 to the earlier level data to generate the level data for $1993-2003 .^{3}$

Electricity demand has grown in terms of its relative importance in total energy consumption. It represents $16.6 \%$ of total final energy demand between 1977 and 1985 and $22.0 \%$ for the last years of the sample period.

\subsection{Unit root and cointegration analysis}

This section considers the main results from the unit root and cointegration tests. We use the Augmented Dickey-Fuller (ADF) t-test to test the null hypothesis of a unit root in the different variables. The optimal lag structure is chosen using the BIC, and deterministic components and 1986 and 1998 dummies were included if statistically significant. $^{4}$

We started by applying the ADF t-tests to output, employment, private investment and aggregate as well as each of the different types of energy consumption, in log-levels, and consistently found that we cannot reject the null hypothesis of non-stationarity at the

\footnotetext{
${ }^{3}$ Note that in the cases of both biomass and of electricity we end up with internally consistent data series that bypass the methodological difficulties present at the data sources. This implies that the discussion below on the issue of structural breaks at the level of unit roots and cointegration tests as well as the VAR specification and estimation deals with actual breaks in the economic relationships and not with methodological data problems.

${ }^{4}$ Since the timing of the structural breaks is known, the use of the standard unit roots tests here and standard cointegration tests below is perfectly appropriate [see, for example, Maddala and Kim, 1998]. In particular, there is no need for the use of more general tests that allow for the presence of structural breaks when the timing of the break is not known. Nevertheless, unit roots and cointegration results obtained using these more general tests are fully consistent with the results discussed in the text and are available from the authors upon request.
} 
$5 \%$ level of significance - see Table 2 . We then tested for stationarity of all the variables in growth rates - see also Table 2. The ADF t-tests suggest that the null hypothesis of a unit root in the growth rates can be rejected for all variables at the $5 \%$ significance level. We take this evidence as a strong indication that stationarity in growth rates is a good approximation for all variables.

We also test for cointegration among the different variables in log-levels - output, employment, private investment and each one of the energy variables. Due to our relatively small sample we use the Engle-Granger procedure, which is less vulnerable than the Johansen procedure to the small sample bias toward finding cointegration when it does not exist [see, for example, Gonzalo and Lee (1998) and Gonzalo and Pitarakis (1999)].

Following the standard Engle-Granger procedure, we perform ADF unit roots tests on the residuals of the linear relationships among the four variables for each of the six modeling cases - aggregate analysis and disaggregated for each of the five types of energy. For each of the six models we consider four different cases each one considering a different endogenous variable in the cointegration relationship. This is because it is possible that one of the variables enters the cointegrating relationship with a statistically insignificant coefficient. In this case, a test that uses such a variable as the endogenous variable would not detect cointegration.

In these cointegration tests, the optimal lag structure was chosen using the BIC, and deterministic components and 1986 and 1998 dummies were included if statistically significant. See Table 3 for the t-statistic for the ADF t-test applied to the residuals of 
each of the four different cointegrating regressions for each of the six models. Test results uniformly suggest that we fail to reject the null hypothesis of no-cointegration.

\subsection{VAR specifications and estimates}

We have determined that all of the variables in log-levels are stationary in growth rates and that they are not cointegrated. Accordingly, we follow the standard procedure in the literature and estimate VAR models in growth rates of the different variables under consideration. Furthermore, these are the growth rates of the variables in their original form and not of the variables purged of any structural breaks that might have been considered in the univariate analysis. This is consistent with the view that dealing with structural breaks at a multivariate level strengthens the analysis by accounting not only for breaks in the individual series but also breaks in the relationships among the variables [see, for example, Bai, Lumsdaine and Stock (1998)].

We estimate six VAR models, all of which include output, employment and investment. In addition, each of the models includes an energy variable - aggregate energy demand or one of five different types of energy demand. The model specifications are determined using the BIC - see the test results on Table 4. In terms of the deterministic components the BIC criterion leads to the selection in all cases of a VAR specification with a constant and a trend. Also, we find that the best VAR specifications include in all cases a structural break in 1986 and, in the cases of the aggregate model and of the model for gas, a structural break in 1998 as well. 


\section{Identifying and Measuring the Effects of Energy Demand Shocks}

We use the impulse-response functions associated with the estimated VAR models to examine the effects of innovations in energy demand. This methodology allows dynamic feedbacks among the different variables to play a critical role, both in the identification of the shocks in energy demand and in measuring the effects of such shocks.

\subsection{Identifying shocks in energy demand}

The key methodological issue in determining the effects of energy demand on economic performance is identifying shocks in energy demand that are truly exogenous, i.e., that are not contemporaneously correlated with shocks in the remaining variables. We have in mind shocks induced by the introduction of environmental regulation, from, for example, the policy instruments considered within the APA's National Program for Climate Change (2006b) for Portugal with the objective of reducing carbon dioxide emissions from fossil fuel combustion activities. In dealing with this issue, we draw from the standard approach in the monetary policy literature [see, for example, Christiano, Eichenbaum and Evans (1996, 1998), and Rudebusch (1998)] adapted in Pereira (2000, 2001) to the analysis of the effects of public investment.

The econometric counterpart to the idea of identifying shocks in energy demand that are truly exogenous is to consider a reaction function, which relates the rate of growth of energy demand to the variables in the relevant information set. In our case, the relevant information set is defined as including past but not current observations of the growth rates of output, employment and private investment and energy demand. The residuals 
from this reaction function reflect the unexpected component of the growth in energy demand and are uncorrelated with shocks in the other variables.

Our reaction function approach can be understood in terms of the standard Choleski decomposition. The Choleski decomposition is a lower triangular decomposition of the variance covariance matrix of the residuals for the estimated VAR system which allows for an exogenous shock to the residuals in a given equation to influence contemporaneously shocks in the residuals of the other equations without being contaminated by such shocks. This allows for the identification and measurement of the effects of the initial shock as a truly exogenous shock. On the flip side, such identifying assumptions are not innocuous in terms of the measurement of the effects of the shocks under consideration. The ordering of the variables matters and in a four variable model there are twenty-four (four-factorial) ways of ordering the variables and therefore identifying assumptions.

Our reaction function approach is equivalent, in the context of the Choleski decomposition, to assuming that shocks in energy demand, while affecting contemporaneously the economic performance of the economy are not affected contemporaneously by such economic performance. This assumption is very reasonable from a conceptual standpoint. Indeed, conceptually, we would expect shocks in energy demand to be either contemporaneously affected by all other variables - output, employment, and investment - but not only some of them or to contemporaneously affect all the other variables but not only some of them. This excludes twelve of the twentyfour alternative identification assumptions and only leaves two sets of possibilities either energy shock are ordered first or ordered last. Conceptually we would not expect 
that economic performance affects contemporaneously energy policy but the reverse is not true, which eliminates six more identifying alternatives. This leaves as the only reasonable identifying alternative our assumption that that shocks in energy demand affect contemporaneously economic performance but the reverse is not true. Finally, in this case, the measurement of the effects of energy shocks on the other variables does not depend on the ordering of the these other variables and so these six remaining cases collapse into just one measurement outcome. This is the central case in Table 6.

Our identification strategy seems to be rather reasonable conceptually. More importantly, when current values of the other variables are included in the reaction functions, in no case are such variables statistically significant. This suggests that our identification strategy is rather reasonable also from a statistical perspective. Nevertheless, and for the sake of completeness, when we report our results under our central identification assumption, the only one conceptually and statistically reasonable, we also include the range of results across all the twenty-four conceivable, but not conceptually or statistically reasonable, identification alternatives within the Choleski decomposition framework.

The reaction functions for aggregate energy demand as well as the different types of energy demand are reported in Table 5. These functions relate the growth in the energy demand variables to the evolution of output, employment and private investment, with a one year lag, according to the selected VAR specification. We find that aggregate changes in energy demand are positively correlated with lagged changes in output and that most of the other effects are not statistically significant - changes in private investment seem to have significant lagged negative effects in the case of coal and 
biomass and positive in the case of petroleum, but these effects seem to cancel out and do not persist at the aggregate level.

\subsection{The impulse-response functions}

We consider the impact of a one percentage point, one-time shock to the rates of growth of the different types of energy demand. We expect these shocks to have at least temporary effects on the growth rates of the other variables. However, even temporary effects on the growth rates of the other variables translate into long-term permanent level effects for these variables. The accumulated impulse-response functions as well as the corresponding $90 \%$ bands that characterize the likelihood shape are presented in Figures 1 - 6. These figures show the cumulative effects of shocks on energy demand based on the historical record of 27 years of data as filtered through the VAR and the reaction function estimates described above. We observe that without exception the accumulated impulse response functions converge within a very short time period suggesting that most of the growth rate effects occur within the first few years after the shocks occur. Accordingly, we present the accumulated impulse response results for only a twenty-year horizon.

The error bands surrounding the point estimates for the accumulated impulse responses convey uncertainty around estimation and are computed via bootstrapping methods. We consider $90 \%$ intervals although bands that correspond to a $68 \%$ posterior probability are the standard in the literature (Sims and Zha, 1999). Employing one standard deviation bands narrows the range of values that characterize the likelihood shape and only serves to reinforce and strengthen our results. Further evidence exists that 
nominal coverage distances may under represent the true coverage in a variety of situations (Kilian, 1998). Similarly, placing too great a weight on the intervals presented in evaluating significance in unwarranted in all but the most extreme cases. Thus, the bands presented are wider than the true coverage would suggest.

The 90\% error bands for our accumulated impulse response functions suggest a high degree of precision in our estimates. This implies that although some of the bands for the accumulated impulse response functions do include zero, in those instances this inclusion reflects the fact that we are using wider bands than those standard in the literature (90\% vis-a-vis 68\%) and that the true coverage is underrepresented, indicating a higher degree of confidence in our central estimates. The exceptions to this rule are the effects of innovations in gas and biomass on employment and more notably the effects of innovations in coal on all variables. Indeed, it is important to highlight that our estimates for the effect of innovations in coal demand show a confidence interval that reinforces the very small impact it has on the economy and does unquestionably include zero effects. ${ }^{5}$

\subsection{Measuring the effects of innovations in energy demand variables}

We estimate the long-term elasticities of the different economic variables with respect to each type of energy demand. The long-term refers to the time horizon over which the growth effects of the innovations disappear, i.e., the accumulated impulse-response functions converge. The accumulated elasticities, therefore, represent the long-term accumulated percentage point changes in the different variables for one long-term

\footnotetext{
${ }^{5}$ The possible zero effects of innovations in gas and biomass on employment are irrelevant for our results and conclusions since they only reflect the indirect effects of these forms of energy on output. The total effects on output are unambiguously positive as displayed in the bottom panels of Figures 4 and 6. In turn, the zero effects of innovations in coal demand only reinforce our general conclusions as will be discussed below.
} 
accumulated percentage point change in energy demand once all the dynamic feedback effects have been considered. Formally, the elasticties are defined as:

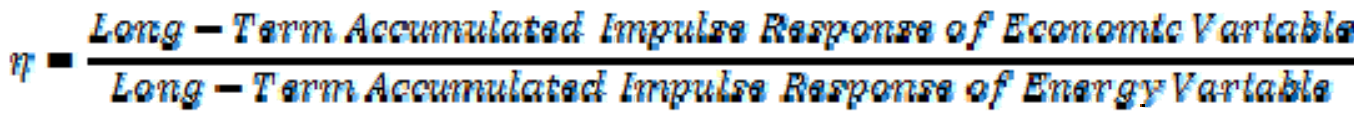

The estimated elasticities under the central orthogonalization assumption as well as the range across all the possible Choleski orthogonalization assumptions are reported in Table 6.

In turn, the corresponding marginal products measure the changes - in thousands of euros in private investment and output and in the number of long-term permanent jobs for a one ton of oil equivalent accumulated increase in final energy demand.

$$
\begin{aligned}
& \text { Leng }- \text { Term Muttipliter }=\Delta \text { Economic Vartable }= \\
& =\eta\left[\frac{1}{\operatorname{card}(t)} \sum_{i=1994}^{2009} \frac{E^{4} \text { conomic Vartable }}{\text { Energy Varlable }}\right] \Delta \text { Energy Vartable }
\end{aligned}
$$

We obtain these figures by multiplying the average ratios of private investment, employment and output to energy demand, for the last ten years, by the corresponding elasticities. The decision to consider the average of the past ten years is designed to reflect the relative scarcity of final demand for the various types of energy considered without letting these ratios be overly affected by business cycle variations. Given the introduction of natural gas in 1998 and the sharp decline in the Portuguese coal mining industry in the last decade, however, the marginal product for both gas and coal were 
obtained from the last five years of the sample. The estimated marginal products are reported in Table 7. See section 6 below for a discussion of the sensitivity of our results to the period chosen for the computation of the marginal effects.

\section{On the Economic Effects of Shocks in Energy Demand}

Our methodological approach captures the dynamic interaction between final energy demand and private investment, employment and output. These dynamic feedback mechanisms are reflected in a policy rule for the evolution of final energy demand as well as in technological and market interactions among private investment, employment and output and between these and energy demand. Within this framework, final energy demand affects economic performance and, at the same time, growth in output, employment and investment affects energy demand through the policy function. The results we now present represent the final outcome of this dynamic process and fully incorporate all of the dynamic feedbacks resulting from the initial exogenous innovation in the relevant energy demand variable.

\subsection{Effects of shocks to aggregate energy consumption}

The top section of Table 7 presents the effects of an exogenous shock to aggregate final energy demand on private investment, employment and output. The empirical results suggest that, over the long-term, energy demand crowds in both private investment and employment. The elasticity of private investment with respect to aggregate energy demand is 2.34 , which corresponds to a long-term marginal product of $€ 3,550$ per toe of final energy demand. In turn, the elasticity of employment with respect 
to aggregate energy demand is 0.48 which suggests that, over the long term, 0.0083 permanent jobs are created for each additional toe of final energy demand (or 1 job per 120.5 toe). Clearly then, final demand for energy has a significant positive impact on output over the long-term with an estimated elasticity of output with respect to energy demand of 0.97 , which corresponds to a long-term marginal product of $€ 6,340$ per toe.

Our results for the impact of shocks to aggregate energy demand on employment and output suggest that energy demand has a positive influence on long-term labor productivity in the economy. As such, the long-term responsiveness of output is greater than the long-term responsiveness of employment. Specifically, in the long term the labor-output ratio in the economy responds to shocks to energy demand with an elasticity of 0.49 .

\subsection{Effects of shocks to different types of energy consumption}

Having established that aggregate energy demand has a significant impact on macroeconomic performance, and in order to facilitate compliance with environmental regulation and appreciate the potential costs associated with fuel switching measures, it is important to identify the macroeconomic impact of the various sources of energy individually. Indeed, the aggregate effects of energy demand on private investment, employment and output hide a wide diversity of effects by type of energy. Consider again Table 7 and note that while all of the sources of energy show a strong and significant impact on macroeconomic activity the effect of coal on economic activity may be overstated.

Private investment generally responds positively to exogenous shocks in most types of energy demand. The strongest effects come from shocks to electricity, petroleum, and 
biomass demand, with elasticities of $1.11,1.01$, and 0.99 . In turn, the elasticity of private investment with respect to shocks in gas consumption is substantially smaller at 0.13 and the elasticity with respect to coal is actually negative at -0.58 .

In terms of the marginal effects on private investment, biomass and electricity consumption have the largest impact with long-term marginal products of €22,710 and $€ 7,900$ per toe, respectively. Gas and petroleum consumption have a smaller, yet important impact on private investment activities, increasing private investment by $€ 3,056$ and €2,360 per toe respectively. Coal demand, however, reduces private investment by $€ 4,265$.

Exogenous shocks to energy demand have an important impact on employment levels as well. The strongest effect results from electricity consumption with an elasticity of 0.44, followed by petroleum consumption, with an elasticity of 0.32 , biomass consumption with 0.03 and gas consumption with 0.02 . On the other hand, the estimated elasticity of employment with respect to coal consumption is small and negative with a value of -0.01 .

Exogenous shocks in the demand for electricity have the largest impact on employment in terms of the marginal effects of shocks to final energy demand. An increase in electricity consumption creates 0.0348 new jobs per toe ( 1 job per 28.7 toe). In turn, shocks in the demand for petroleum and biomass generate 0.0084 and 0.0083 new jobs per toe, respectively ( 1 job per 119.0 and 120.5 toe) while an increase in gas consumption by a toe corresponds to the creation of 0.0044 new jobs over the long-term (1 job per 227.3 toe). As with private investment, increased coal consumption has a negative impact on employment, leading to a loss of 0.0042 jobs (1 job per 238.1 toe). 
Given the impact of each type of energy on private investment and employment, the relative importance of their impact on output is no surprise. Electricity consumption has the strongest effect with an output elasticity of 0.66 while the output elasticities with respect to petroleum and biomass consumption are 0.40 and 0.24 , respectively. In turn, the output elasticities of gas consumption and coal consumption with respect to output are much smaller at 0.04 and 0.01 , respectively. The positive impact of coal on output highlights uncertainty in the parameter estimates, particularly when we consider the negative impact induced by the final demand for coal on private investment and employment. This reflects the fact that the error bands surrounding the point estimates for coal include zero.

Of the various types of energy considered, shocks to the demand for biomass and electricity have the largest impact on output in terms of their marginal products. Increases in final demand for biomass and electricity by a toe generate a long term increase in output of approximately €23,340 and €19,950, respectively. The remaining effects are substantially smaller. The effects of increased gas and petroleum consumption on output are $€ 4,257$ and $€ 4,040$ per toe, respectively. Coal consumption increases output by $€ 3,332$ per ton but may in fact have a substantially smaller effect.

\section{On the Effects of Reductions in Carbon Dioxide Emissions}

The economic impact of policies to reduce carbon dioxide emissions from fossil fuel combustion activities will depend on the type of energy that is targeted by regulation. Thus, the impact of each type of energy on the macroeconomic variables considered is central to estimating the economic costs of fuel switching measures. 
Reducing carbon dioxide emissions from fossil fuel combustion activities requires a reduction in the consumption of fossil fuels that contain large amounts of carbon. As mentioned above, this can be achieved through a direct reduction in the quantity of fuel consumed or through fuel-switching. This section seeks to explore the relationship between fuel consumption, carbon dioxide emissions and economic performance by estimating marginal abatement costs for carbon dioxide emissions resulting from reductions in fossil fuel consumption from policies targeting specific sources of energy.

\subsection{On the carbon content of different fossil fuels}

The hydrogen and carbon contained in fossil fuels generates the potential for heat and energy production. Carbon is released from the fuel upon combustion; $99.0 \%$ of the carbon released from the combustion of petroleum, 99.5\% from natural gas, and 98.0\% from coal, oxidizes to form carbon dioxide. Thus, the carbon emitted from fossil fuel combustion activities, once oxidized, can be used to compute the carbon dioxide emissions by considering the ratio of the molecular weight of carbon dioxide to carbon. Together, the quantity of fuel consumed, its carbon factor, oxidation rate, and the ratio of carbon dioxide to carbon are used to compute the amount of carbon dioxide emitted from fossil fuel combustion activities in a manner consistent with the Intergovernmental Panel for Climate Change (2006) reference approach. These considerations suggest a linear relationship between carbon dioxide emissions and fossil fuel combustion activities.

Table 8 presents the relevant information for determining the carbon dioxide emission factor for each source of energy under consideration. We convert tons of oil equivalent units to tera-joules of energy to ensure that that the carbon emission factor is in the 
appropriate units. We then adjust for incomplete combustion via the oxidation rate and determine the total amount of carbon that is released to the atmosphere. Finally, because we are ultimately interested in the quantity of carbon dioxide released into the atmosphere, we multiply the quantity of carbon by 44/12, the ratio of the molecular weight of carbon dioxide $\left(\mathrm{CO}_{2}-12+16(2)\right)$ to carbon (12).

This information allows us to determine the impact of reducing carbon dioxide emissions from fossil fuel combustion activities through a reduction in each of the types of energy considered. We determine the aggregate impact over a twenty year period and present results on an annual basis. Petroleum combustion generates 3.04 tons of $\mathrm{CO}_{2}$ per toe. Coal contains the largest quantity of carbon and as a result generates $4.04 \mathrm{t} \mathrm{CO}_{2}$ per toe. Natural gas, on the other hand, contains the least carbon relative to its hydrogen content and therefore has the lowest emission factor generating $2.34 \mathrm{t} \mathrm{CO}_{2}$ per toe.

In specific circumstances the carbon released upon the combustion of biomass may be equal the carbon uptake of the sink during growth and as such biomass combustion as a fuel source is not included in the national greenhouse gas inventories. As a result, a closed circuit of biomass growth and combustion to satisfy energy demand is often recommended as an appropriate method for reducing greenhouse gas emissions. Although not constrained by climate policy, the effective utilization of biomass for energy consumption is limited by land and water requirements. Generally, the emission factor for biomass considered in the national greenhouse gas inventories is $4.59 \mathrm{t} \mathrm{CO}_{2}$ per toe (APA, 2006a).

The case of electricity is more complex. Carbon dioxide emissions from electricity consumption depend largely on the composition of the fuels used in generation and the 
thermal efficiency of the conversion technologies. Electricity generation in Portugal is primarily fuelled by thermal sources - coal, diesel, fuel oil, natural gas, waste, and biomass - and by hydropower and wind. Thermal power and hydropower tend to exhibit an inverse relationship in Portugal consistent with the availability of hydrological resources and precipitation trends. In 2002, hydropower accounted for about $17.8 \%$ of total electricity generation, a substantial decrease in comparison to 2001 when hydropower accounted for $31.5 \%$ of total electricity generation. As such the average annual emission factor for electricity generation over the past ten years is used to determine the effect of reductions in carbon dioxide emissions from electricity generation.

The carbon dioxide emission factor for electricity was constructed from the energy balances complied by the DGE and the APA. Primary energy demand for use in electricity generation, including thermal, hydrological and renewable energy resources, give a complete picture of the quantity of carbon dioxide produced in the electric power industry. Each fuel's carbon dioxide emission factor is used to compute total carbon dioxide emissions from fossil fuel combustion in the industry. Naturally, the emission factor for hydrological and renewable energy resources is equal to zero. Total carbon dioxide emissions are then divided by total electricity demand to determine the industry's emission factor, 5.22.

Notice that the aggregate emission factor for electricity is greater than the emission factor for each fuel source used in the generation of electric power. This results from inefficiencies in transmission and particularly in generation of electricity. Thermal efficiencies approach a technical limit and improve with plant size and vintage, but even 
under these conditions a greater quantity of the primary fossil fuel vectors, coal, fuel oil and diesel is required to produce one ton of oil equivalent of electricity, which produces the high emissions factor for this industry.

Finally, following a procedure analogous to the computations above allows us to obtain an aggregate energy carbon dioxide emission factor for carbon dioxide emissions from fossil fuel combustion activities for the economy. We consider carbon dioxide emissions from fossil fuel combustion activities and not those from industry, waste, forestry and land use change. As such, to compute the aggregate economy-wide emission factor we consider total energy consumption and total carbon dioxide emissions from energy consumption. The implied average aggregate emissions intensity for aggregate energy consumption in the economy between 2000 and 2003 is $3.31 \mathrm{t} \mathrm{CO}_{2}$ per toe.

At the aggregate level, carbon dioxide emissions from the final demand for petroleum account for 59.79\% of total carbon dioxide emissions between 1993 and 2003. Electricity is the second largest source contributing $33.72 \%$ of the total carbon dioxide emissions. In turn, the final demands for coal and gas consumption generate $3.98 \%$ and $2.51 \%$ of total carbon dioxide emissions, respectively. Carbon dioxide emissions from biomass are not included in the national inventory report and have therefore been excluded from total carbon dioxide emissions used to compute the emission factor for aggregate energy consumption.

\subsection{Effects of reductions in carbon dioxide emissions by type of fossil fuel}

Marginal abatement costs for carbon dioxide emissions from the combustion of petroleum, coal, gas, biomass and electricity are presented in Table 9. These costs reflect the impact of carbon dioxide emissions from the final demand for the various 
disaggregate energy sources on private investment, employment and output. Reductions in final demand for coal and petroleum have the lowest cost to economic activity per ton of carbon dioxide abatement. On the other hand, reducing the final demand for electricity and biomass implies significantly greater macroeconomic costs, with natural gas somewhere in between.

We estimate that uniform standards across all energy sources would generate aggregate marginal abatement costs of $€ 95.74$ per ton of carbon dioxide. Private investment would fall by $€ 53.55$; over the long term, 0.0025 permanent jobs would be lost for every ton of carbon dioxide abatement from uniform standards across the final demand for each type of energy ( 1 job for every 400 tons of $\mathrm{CO}_{2}$ ). These aggregate effects, however, hide a wide range of effects for policies targeting the final demand for specific sources of energy.

The macroeconomic impacts of policy innovations in the demand for petroleum are relatively modest. As a result, marginal abatement costs for carbon dioxide emissions from petroleum combustion activities are also relatively low. Carbon dioxide abatement activities associated with petroleum consumption would reduce private investment by $€ 38.83$ and eliminate 0.0028 jobs over the long term per ton of carbon dioxide ( 1 job for every 357.1 tons of $\mathrm{CO}_{2}$ ). Environmental policies that focus carbon abatement activities on reducing petroleum consumption would cost €66.52 per ton per year.

Marginal abatement costs for carbon dioxide from coal combustion activities are $€ 45.62$ per ton per year, but may be substantially overstated. Because coal has a negative impact on private investment and employment, environmental policies that target coal 
consumption increase private investment by $€ 52.90$ per ton and create 0.0010 new jobs ( 1 job for every $1,000.0$ tons of $\mathrm{CO}_{2}$ ).

While gas generally has the lowest carbon emission factor of all fossil fuels, it has a very small impact on the economy. Marginal abatement costs for policies that target gas consumption are $€ 91.07$ per ton per year. These costs reflect a $€ 65.38$ per ton of $\mathrm{CO}_{2}$ reduction in private investment and the loss of 0.0019 jobs ( 1 job for every 526.3 tons of $\left.\mathrm{CO}_{2}\right)$.

Biomass has a large impact on economic activity. Although biomass is not accounted for in national greenhouse gas inventories, we consider the private investment, employment and output potential of the carbon embodied in biomass energy resources and the potential for economic growth therein. The carbon embodied in biomass generates $€ 254.23$ output per ton of carbon dioxide emitted. One ton of carbon dioxide resulting from biomass combustion increases private investment by $€ 247.32$ and creates 0.0018 new jobs (1 job for every 555.6 tons of $\mathrm{CO}_{2}$ ).

Electricity consumption has a large impact on economic performance. In fact, each ton of carbon dioxide reduced through abatement activities targeting reductions in electricity consumption costs $€ 191.13$. Similarly, each ton of carbon dioxide abatement resulting from policies directed at reducing electricity consumption reduces private investment by $€ 75.64$ and eliminates 0.0067 jobs ( 1 job for every 149.3 tons of $\mathrm{CO}_{2}$ ).

In general our results suggest that the significant macroeconomic cost differentials associated with final demand for the various energy sources considered can be exploited in order to achieve a net reduction in carbon dioxide emissions while promoting economic growth through selective fuel switching activities. Specifically, our results 
suggest that emission reductions achieved through reductions in coal and oil demand have substantially lower economic costs than equal emission reductions due to cuts in gas, electricity or biomass consumption.

As a way of illustrating the point, our results allow us to estimate the impact of the 11 Mt reduction in carbon dioxide emissions from fossil fuel combustion activities necessary to comply with the Portuguese commitment under the European Union Burden Sharing Agreement and which is considered within the National Program for Climate Change in 2006 (Resolucao do Conselho de Ministros n. 104/2006; APA 2006c). Uniform standards across all final demand energy consumers would reduce GDP by 1.053 billion euros, or $0.73 \%$.

Given the cost differentials among the various types of energy, however, uniform standards are far from efficient. In fact, it is clearly possible to simultaneously reduce emissions while promoting economic activity through well designed fuel switching measures. To illustrate our point, consider for example, policy measures that promote fuel switching in cement manufacturing or the chemicals and plastics industry can reduce carbon dioxide emissions from fossil fuel combustion by 2,500 tons by reducing the consumption of coal by about $3.8 \%$ in the chemical and plastics industry, or 1,237 tons (5000 tons of CO2 from coal), and offsetting part of the reduction in energy demand by an increase in natural gas consumption of 1070 tons (2500 tons of CO2 from natural gas) for a net increase in GDP of 21,054 euros. In fact, given the fact that we cannot conclusively say that the impact of coal consumption is different from zero and the range of likely values is relatively limited, the potential gains may be significantly greater. Of course, further work would be necessary in order to optimize fuel switching policies by 
considering the substitution elasticities, the impact of decreasing marginal returns as well as incentive schemes that can address equity issues in order to implement these types of fuel switching policies.

\subsection{On the Robustness of the Estimates of the Marginal Abatement Costs}

A key consideration in understanding the relationship between energy consumption and economic performance, and therefore on the effects of reductions in carbon dioxide emissions, is the relative scarcity of the energy source under consideration. In the computations of the marginal effects of shocks in energy demand and thereby on the marginal abatement costs for different sources we considered the energy to output ratios for a number of years toward the end of the sample period. The idea is to capture the scarcity at the margin, the last years of the sample, while minimizing business cycle variations by not subjecting our estimates to peculiarities associated with a single year, the last year or the sample period. In Table 10 we report the sensitivity of our estimates of the marginal products and abatement costs to the period considered in their computation. ${ }^{6}$

Due to the relative stability of petroleum, biomass, electricity, in the computation of the marginal effects for these fuel types, we consider the average over the last ten years. Naturally our results are not very sensitive to the time horizon considered. As we consider shorter periods closer to the end of the sample, petroleum and electricity we find progressively but only slightly decreasing marginal product and marginal abatement cost

\footnotetext{
6 It should be noted that the elasticity figures proper are obtained directly from the VAR estimates and the corresponding accumulated impulse response function and therefore are calculated taking into consideration all relevant dummy variables and are not subject to change over time. The marginal products and the abatement costs which are obtained from these elasticities using energy - output ratios, however, reflect changes in the relative scarcity of the different energy types and do change over time. The later are the focus of this section.
} 
estimates. The opposite is true with biomass. At any rate, our estimates for petroleum, biomass, and electricity are very stable and robust.

Coal and gas, however, present a significantly different situation. On one hand, the introduction and expansion of natural gas transportation and distribution infrastructure after 1998 has contributed to a very significant increase in the final demand for natural gas. This sharp increase in the consumption of natural gas clearly induces a sharply decreasing trend in the estimates of its effect on output and of its marginal abatement costs. On the other hand, the absolute decline in the Portuguese coal mining industry in the recent past together with reductions in the final demand for coal leads to sharply increasing estimates of its marginal effect on output and of its marginal abatement costs.

Our results discussed in the body of the paper assume ten year averages for the computation of the effects of petroleum, biomass, and electricity and five years for coal and gas. Our main conclusion based on these results is that emission reductions achieved through reductions in coal and oil demand have substantially lower economic costs than equal emission reductions due to cuts in gas, electricity or biomass consumption. An important question, however, is how robust this conclusion is to the choice of the time period for which these figures are calculated. If we were to consider ten-year averages for all fuel types we would reach the same qualitative conclusion although the marginal abatement costs of gas consumption would be much higher than reported and for coal much lower. If on the other hand we were to consider only the last year of the sample we would be more inclined to consider the costs of reducing coal consumption as on the high end and the costs of reducing gas on the lower end - a reversal of the main conclusion for these two types of fuel. Again, it is important to highlight that these results may 
substantially overstate the impact of coal on the economy as the likelihood curves include the possibility of coal having no effect whatsoever. At any rate, the central point that there are substantial fuel switching opportunities capable of reducing emissions and indeed generating favorable economic outcomes would still stand, even more so.

\section{Conclusions}

The objective of this paper is to empirically estimate the impact of reductions in carbon dioxide emissions from fossil fuel combustion activities on economic performance in Portugal in order to evaluate the economic costs of policies to reduce carbon dioxide emissions and to identify the main guidelines in designing such policies. We are particularly interested in assessing the possible existence of a trade-off between reductions in carbon dioxide emissions and economic performance when one considers the overall economic costs of climate policies by considering the differences in the economic impact and carbon content across different fuel types.

Empirical results suggest that unanticipated shocks in energy demand have a significant impact on private investment, employment and output. A permanent one ton of oil equivalent decrease in aggregate energy consumption decreases output in the long term by $€ 6,340$. This aggregate result, however, hides a great disparity of disaggregate effects. In fact, a permanent one ton of oil equivalent reduction in biomass and electricity consumption reduces output in the long term by €23,340 and €19,950 respectively. Gas, petroleum and coal consumption, on the other hand, have a much smaller impact on economic activity. A one time, one ton of oil equivalent reduction in gas consumption 
reduces output by $€ 4,260$; a reduction in petroleum consumption reduces output by $€ 4,040$; and a reduction in coal consumption reduces output by $€ 3,330$. These results suggest that although increases in energy consumption have positive economic effects across the board, policies that are designed to promote economic performance are better served if based on increased consumption of biomass and electricity.

These results allow us to estimate the costs of environmental policies designed to reduce carbon dioxide emissions from fossil fuel combustion activities because carbon dioxide emissions are linearly related to the fuel vector consumed. We estimate that a uniform reduction across each type of energy would lead to an aggregate marginal abatement cost of $€ 95.74$ per ton of carbon dioxide. This is a first rough estimate of the overall economic costs of policies designed to reduce carbon dioxide emissions. At this level one may conclude that uniform, across the board reductions in carbon emissions would have a clear negative effect on economic activity. Hence, at the aggregate level there is clear evidence for a trade-off between economic performance and a reduction in carbon emissions.

Naturally, due to the diverse economic impact of different fuels as well as their different carbon content, the aggregate marginal abatement costs hide a wide variety of disaggregated results. The marginal abatement costs for carbon dioxide emissions are $€ 66.52$ per ton of carbon dioxide per year for emissions from oil, €45.62 from coal, $€ 91.07$ from gas, €254.23 from biomass, and €191.13 from electricity. Clearly, emission reductions achieved through reductions in coal and oil demand have substantially lower economic costs than equal emission reductions due to cuts in gas, electricity or biomass consumption. As a corollary, the macroeconomic impact of policies designed to reduce 
carbon dioxide emissions will depend crucially on the type of fuel targeted by each policy and the choice of such policies must be sensitive to their macroeconomic impact, in addition to the their feasibility, potential capacity for emission reductions, and direct costs.

There is, however, a more important policy implication from our disaggregated results. The sharp differences in the marginal abatement costs across different types of fuels suggests that restructuring the composition of fuel demand could be a very powerful tool in minimizing the economic costs of reducing carbon dioxide emissions. Although direct energy system costs may increase as a result of a regulatory induced shift to higher cost, low carbon fuels, our results clearly indicate that, once the impact of energy consumption on economic activity is considered, fuel switching is a no regrets environmental policy option capable of reducing carbon dioxide emissions from fossil fuel combustion activities while minimizing or even eliminating the economic costs of such reductions. To put in another words, fuel switching has the potential to be a way out of the trade-off identified at the aggregate level between reductions in carbon dioxide emissions and economic performance.

Specifically, our empirical results suggest that policies should focus on shifting energy demand from low marginal abatement cost fuels such as coal and petroleum to fuels such as natural gas and electricity with high marginal abatement costs and marginal effects on the economy. Biomass, although limited by land and water requirements as well as conservation and biodiversity concerns, also represents a very powerful avenue for satisfying final energy demand while substituting away from fossil fuels. Such fuel switching is consistent with reducing overall carbon emissions without jeopardizing 
economic performance but more importantly introduces the possibility of designing fuel switching policies in a way that both reduces carbon dioxide emissions and enhances economic performance.

It should be noted that traditional fuel switching policies based exclusively on the carbon content of different fuels could also suggest a greater use of natural gas, electricity and biomass and a lesser use of coal and oil. Our results based on the overall economic impact of such policies, however, suggest that the underlying costs of fuel switching measures are significantly lower than those traditionally considered.

By establishing the relevance of fuel switching in Portugal, this study opens the door to several natural extensions which would allow us to fine tune our policy conclusions. First, one should consider the impact of carbon dioxide emissions from fossil fuel combustion activities on economic activity by sector. Second, the results may also be extended to assess the regional decomposition of these effects in order to assess the geographical incidence of the costs of reducing greenhouse gas emission in Portugal. In both cases the extensions would provide sector-specific and region-specific estimates of the marginal abatement costs for carbon dioxide emissions from energy consumption, contributing to the design of environmental policies and an appreciation of the incidence of compliance costs in climate policy by understanding the impact of fuel consumption. Besides the issue of fuel switching, the implications for possible markets for tradable emission permits would be equally important by highlighting the possible existence of arbitrage opportunities across sectors or regions.

Finally, and although the results in this paper are very important form a policy perspective in Portugal, their interest is not merely parochial. From a conceptual 
perspective, we shift the focus of the policy design from the consideration of the carbon content of each fuel to the economic cost of reducing a given amount of carbon emissions for each fuel. In this context, the exact identification of the marginal abatement costs for different fuels and the potential for fuel switching as a way out of the perceived trade off between reducing carbon dioxide emissions and promoting robust economic performance are questions with universal relevance. Furthermore, the potential for fuel switching, while important for advanced industrialized nations, may be particularly important for developing nations where the difficulties in promoting fuel efficiency are more pronounced and the resources for investing in the development and deployment of energy efficient technologies more limited. At last but not the least, the application of this approach at the international level would allow for the identification of arbitrage opportunities across countries for possible markets for tradable emission permits. 


\section{References}

1. Agencia Portuguesa do Ambiente (2006a). http://www.apambiente.pt/politicasambiente/Ar/InventarioNacional/Paginas/defau lt.aspx

2. Agencia Portuguesa do Ambiente, (2006b). National Program for Climate Change - Programa Nacional para as Alterações Climáticas. Anexo Técnico: Oferta de Energia, Industria, Construção e Obras Públicas e Outros.

3. Agencia Portuguesa do Ambiente, (2006c). Fourth National Communication to the United Nations Framework Convention on Climate Change: First national Communication in the context of the kyoto Protocol. Amadora. 2006. http://www.apambiente.pt/politicasambiente/AlteracoesClimaticas/RelatNacion/C omunicacaoNacional/Documents/4CN_PT\%20_EN_final_.pdf

4. Asafu-Adjaye, J. (2000), “The relationship between energy consumption, energy prices and economic growth: time series evidence from Asian developing countries,” Energy Economics, 22(6):615-625.

5. Bai, Jushan, Robin L. Lumsdaine, and James H. Stock (1998), "Testing for and Dating Common Breaks in Multivariate Time Series." Review of Economic Studies, 65: 395-432.

6. $\quad$ Banco de Portugal (1997), Séries Longas para a Economia Portuguesa, Lisboa: Banco de Portugal.

7. Barker, T., P. Ekins, and T. Foxon. (2007). 'Macroeconomic effects of efficiency policies for energy-intensive industries: The case of the UK Climate Change Agreements, 2000-2010,” Energy Economics, 29:760-778.

8. Cheng, B.S. and Tin Wei Lai, (1997). “An investigation of co-integration and causality between energy consumption and economic activity in Taiwan," Energy Economics, 19(4):435-444.

9. Chen, W., Z. Wu, J. He, P. Gao and S. Xu. (2005). "Carbon emission control strategies for China: A comparative study with partial and general equilibrium versions of the China MARKAL model,” Energy, 32(1):59-72.

10. Christiano, L., M. Eichenbaum, C. Evans, (1996). “The effects of monetary policy shocks: evidence from the flow of funds," Review of Economics and Statistics 78(1):16-34.

11. Christiano, L., M. Eichenbaum, C. Evans, (1998). "Monetary policy shocks: what have we learned and to what end?” NBER 6400. 
12. Commission of the European Communities (1999), European Economy 69, Brussels: Commission of the European Communities.

13. Crompton, P. and Yanrui Wu. (2005). "Energy Consumption in China: past trends and future directions,” Energy Economics, 27: 195-208.

14. Direccao Geral de Energia e Geologia. (2008). Balancos Energeticos. http://www.dgge.pt/

15. Energy Information Administration, U.S. Department of Energy (2002). "Model Documentation Report: Macroeconomic Activity Module of the National Energy Modelling System,” Office of Integrated Analysis and Forecasting.

16. Francis, B.M., L. Mosley and S. O. Iyare. (2007) "Energy Consumption and projected growth in selected Caribbean countries,” Energy Economics, 29: 12241232.

17. Gaskins, D. W. Jr., and J. P. Weyant. (1993) "Model comparisons of the costs of reducing $\mathrm{CO}_{2}$ emissions," American Economic Review 83(2):318-23.

18. Gonzalo, J. and T. Lee, (1998) "Pitfalls in testing for long run relationships," Journal of Econometrics 86: 129-54.

19. Gonzalo, J. and J-Y Pitarakis, (1999). Dimensionality Effect in Cointegration Analysis, in Festschrift in Honour of Clive Granger, edited by R. Engle and $\mathrm{H}$. White: 212-229. Oxford University Press.

20. Grubb, M., J. Edmonds, et al. (1993). "The costs of limiting fossil-fuels CO2 emissions: a survey and analysis," Annual Review of Energy and the Environment 18: 397-478.

21. Hue, G. J. Y. And H.M. Xu. (2000). "Impact of mitigating $\mathrm{CO}_{2}$ emissions on Taiwan's economy: a fuzzy multi-objective programming approach," Environmental Economics and Policy Studies, 3: 335-345.

22. Intergovernmental Panel on Climate Change, (2006). 2006 IPCC Guidelines for National Greenhouse Gas Inventories.

http://www.ipccnggip.iges.or.jp/public/2006gl/pdf/2_Volume2/V2_6_Ch6_Reference_Approach. pdf

23. Jorgenson, D., (1998). Growth Volume 2: Energy, the Environment, and Economic Growth. The MIT Press, Cambridge, Massachusetts.

24. Kilian, Lutz. (1998). "Small-Sample Confidence Intervals for Impulse Response Functions”. The Review of Economics and Statistics, Vol. 80. No.2:218-230. 
25. Lasky, M., (2003). "The Economic costs of reducing emissions of greenhouse gases: a survey of economic models," Congressional Budget Office, Macroeconomic Analysis Division, Washington D.C.

26. Manne, A. S. and R. G. Richels, (1992). Buying Greenhouse Gas Insurance: The Economic Costs of $\mathrm{CO}_{2}$ Emission Limits, MIT Press, Cambridge, Massachusetts.

27. Masih, A.M.M, and Masih, R., (1996). "Energy consumption, real income and temporal causality: results from a multi-country study based on cointegration and error-correction modelling techniques,” Energy Economics, 18(3):165-183.

28. Ministério das Finanças (2006). The Portuguese Economy, Lisboa: DGEP.

29. Nordhaus, W., (1993). "Reflections on the economics of climate change," Journal of Economic Perspectives, 7(4):11-25.

30. Oh, Wankeun and Kihoon Lee, (2004). "Causal relationship between energy consumption and GDP revisited: the case of Korea 1970-1999," Energy Economics, 26: 51-59.

31. Pereira, A. (2000), "Is all public capital created equal?” Review of Economics and Statistics 82: 513-18.

32. Pereira, A. (2001), "Public capital formation and private investment: what crowds in what?” Public Finance Review 29: 3-25.

33. Perobelli, F.S., R.S. Mattos, E.A. Haddad and M.P.N Silva. (2007) “An integrated econometric + input-output model for the Brazilian economy: an application to the energy sector.” Ecomod2007: International Conference on Policy Modeling. Sao Paulo, Brazil, July 11-13, 2007.

34. Resolucao do Conselho de Ministros n. 104/2006. http://www.dre.pt/pdf1sdip/2006/08/16200/60426056.PDF

35. Rudebusch, G., (1998), "Do Measures of monetary policy in a VAR make sense?” International Economic Review 39: 907-31.

36. Scott, M.J., J. M. Roop, R. W. Schultz, D.M. Anderson and K.A. Cort. (2008). "The impact of DOE building technology energy efficiency programs on U.S. employment, income and investment," Energy Economics, 30 (2), 2283-2301

37. Sims, Christopher A. and Tao Zha. (1999). "Error Bands for Impulse Responses.” Econometrica. Vol. 67, no. 5. pp. 1113-1155. 
38. Stern, D. I. (1993) "Energy and economic growth in the USA - A multivariate approach,” Energy Economics, 15(2):137-150.

39. Stern, D. I. (2000), "A multivariate cointegration analysis of the role of energy in the US macroeconomy,” Energy Economics, 22(2): 267-283.

40. Zhang, Z.X. and H. Folmer. (1998). "Economic modeling approaches to cost estimates for the control of carbon dioxide emissions," Energy Economics, 20: 101-120. 
Table 1: Decomposition of Final Energy Demand

\begin{tabular}{|c|c|c|c|c|c|}
\hline & Petroleum Share & Coal Share & Gas Share & Biomass Share & Electricity Share \\
\hline 1977 & 70.74 & 4.37 & 1.09 & 9.13 & 14.67 \\
\hline 1978 & 70.28 & 4.18 & 1.12 & 9.14 & 15.29 \\
\hline 1979 & 70.77 & 3.89 & 1.03 & 8.34 & 15.98 \\
\hline 1980 & 70.53 & 3.60 & 1.00 & 8.46 & 16.40 \\
\hline 1981 & 70.97 & 2.90 & 1.21 & 8.59 & 16.33 \\
\hline 1982 & 71.30 & 2.30 & 1.09 & 8.66 & 16.65 \\
\hline 1983 & 69.03 & 3.48 & 1.31 & 8.61 & 17.57 \\
\hline 1984 & 67.93 & 4.23 & 1.23 & 8.52 & 18.09 \\
\hline 1985 & 65.20 & 5.89 & 1.23 & 9.17 & 18.49 \\
\hline 1986 & 62.62 & 7.20 & 1.26 & 10.44 & 18.49 \\
\hline 1987 & 62.95 & 7.31 & 1.16 & 10.11 & 18.47 \\
\hline 1988 & 63.24 & 7.32 & 1.14 & 9.63 & 18.66 \\
\hline 1989 & 63.24 & 7.02 & 1.04 & 9.83 & 18.87 \\
\hline 1990 & 64.59 & 6.29 & 0.90 & 8.86 & 19.37 \\
\hline 1991 & 65.22 & 6.00 & 0.83 & 8.39 & 19.56 \\
\hline 1992 & 65.90 & 5.83 & 0.86 & 8.00 & 19.40 \\
\hline 1993 & 66.24 & 5.62 & 0.87 & 7.83 & 19.43 \\
\hline 1994 & 65.82 & 5.66 & 0.66 & 7.66 & 20.19 \\
\hline 1995 & 65.86 & 5.05 & 0.77 & 7.51 & 20.80 \\
\hline 1996 & 66.08 & 5.05 & 0.79 & 7.27 & 20.82 \\
\hline 1997 & 66.70 & 4.04 & 1.09 & 7.02 & 21.13 \\
\hline 1998 & 66.47 & 3.26 & 2.52 & 6.61 & 21.14 \\
\hline 1999 & 64.82 & 2.81 & 4.20 & 6.39 & 21.77 \\
\hline 2000 & 63.30 & 3.30 & 5.96 & 5.94 & 21.50 \\
\hline 2001 & 63.65 & 1.45 & 6.87 & 5.98 & 22.05 \\
\hline 2002 & 63.13 & 1.11 & 7.45 & 5.78 & 22.52 \\
\hline 2003 & 62.06 & 0.88 & 7.93 & 5.90 & 23.24 \\
\hline $1977-85$ & 69.64 & 3.87 & 1.15 & 8.74 & 16.61 \\
\hline 1986-97 & 64.87 & 6.03 & 0.95 & 8.55 & 19.60 \\
\hline 1998-03 & 63.91 & 2.14 & 5.82 & 6.10 & 22.04 \\
\hline $1977-03$ & 66.25 & 4.45 & 2.10 & 8.07 & 19.14 \\
\hline
\end{tabular}

Source: Authors' computation based on DGE data. 
Table 2: ADF Unit Root Tests

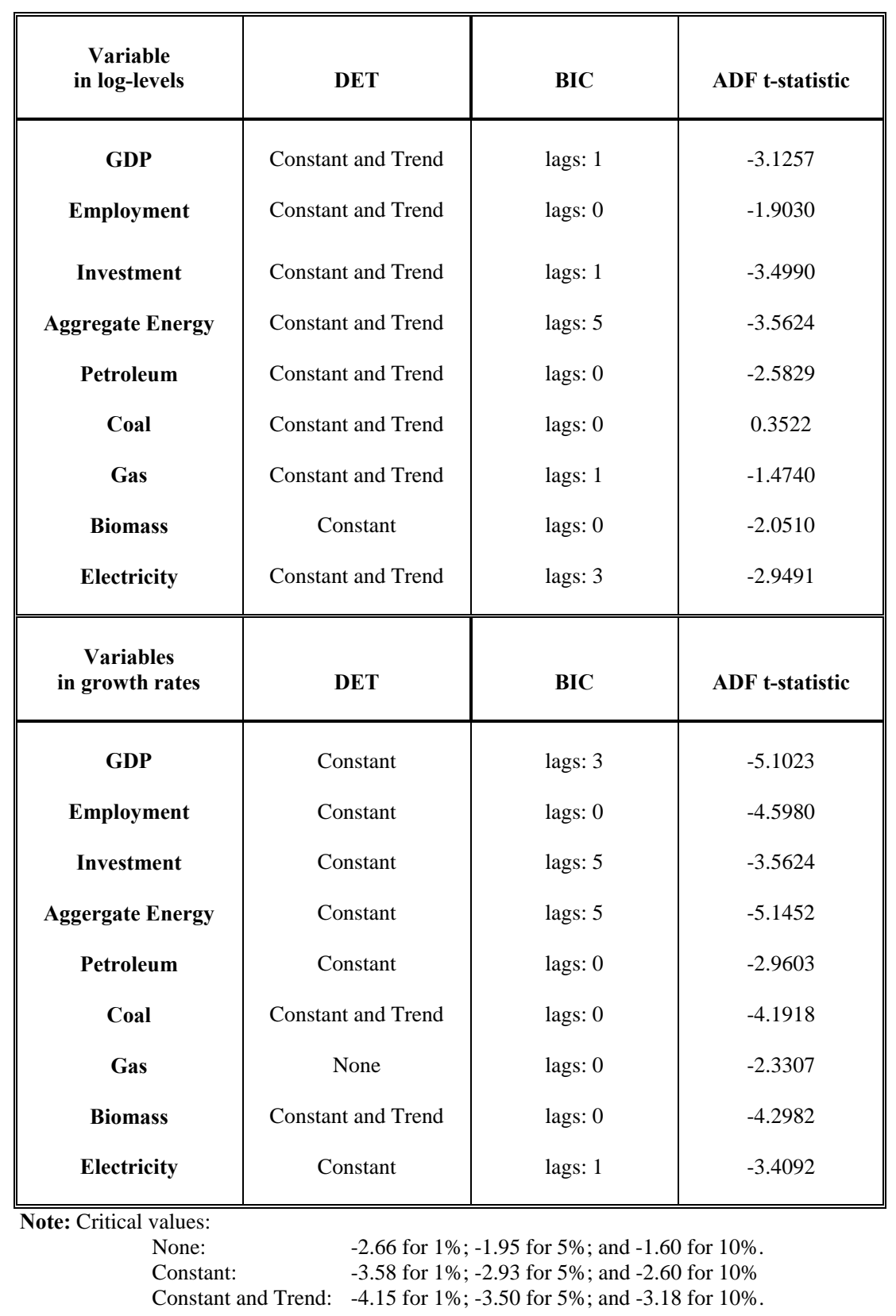


Table 3: Engle-Granger Tests of the Null Hypothesis of No-Cointegration

\begin{tabular}{|c|c|}
\hline $\begin{array}{c}\text { Endogenous variable } \\
\text { in the cointegration equation } \\
\text { in log-levels }\end{array}$ & ADF t-statistic \\
\hline GDP & -1.6464 \\
\hline Employment & -2.1855 \\
\hline Private Investment & -1.6794 \\
\hline Agg energy & -3.3172 \\
\hline GDP & -1.2519 \\
\hline Employment & -1.5630 \\
\hline Private Investment & -2.4157 \\
\hline Petroleum & -2.7197 \\
\hline GDP & -2.9240 \\
\hline Employment & -3.3455 \\
\hline Private Investment & -1.7084 \\
\hline Coal & -3.1151 \\
\hline GDP & -2.4121 \\
\hline Employment & -2.5883 \\
\hline Private Investment & -1.3541 \\
\hline Gas & -2.4464 \\
\hline GDP & -1.7081 \\
\hline Employment & -1.6452 \\
\hline Private Investment & -2.2688 \\
\hline Biomass & -2.3082 \\
\hline GDP & -1.6049 \\
\hline Employment & -2.1676 \\
\hline Private Investment & -1.8099 \\
\hline Electricity & -1.9239 \\
\hline
\end{tabular}

Note: Critical values: -5.95 for $1 \%$; -5.04 for $5 \%$; and -4.61 for $10 \%$ 
Table 4: BIC Tests for the VAR Specification

\begin{tabular}{|c|c|c|c|c|c|}
\hline VAR with ... & & Dummy & None & Constant & Constant and Trend \\
\hline \multirow{4}{*}{$\Delta$ Aggregate Energy } & \multirow{4}{*}{ VAR(1) } & --- & -29.43059 & -29.81750 & -30.24883 \\
\hline & & 1986 & -29.59091 & -30.28714 & -30.80473 \\
\hline & & 1999 & -29.91158 & -30.44715 & -30.52606 \\
\hline & & 1986,1999 & -30.24449 & -30.73582 & -30.90924 \\
\hline \multirow{2}{*}{$\Delta$ Petroleum } & \multirow{2}{*}{ VAR(1) } & --- & -28.91055 & -29.11829 & -29.26935 \\
\hline & & 1986 & -29.09068 & -29.40695 & -29.71740 \\
\hline \multirow{2}{*}{$\Delta$ Coal } & \multirow{2}{*}{ VAR(1) } & -- & -24.31833 & -24.52800 & -24.62713 \\
\hline & & 1986 & -24.44948 & -24.79949 & -25.05929 \\
\hline \multirow{4}{*}{$\Delta$ Gas } & \multirow{4}{*}{ VAR(1) } & --- & -23.57165 & -23.77050 & -23.93248 \\
\hline & & 1986 & -23.67860 & -24.06731 & -24.53598 \\
\hline & & 1999 & -23.96515 & -24.22931 & -24.29211 \\
\hline & & 1986,1999 & -24.18798 & -24.57198 & -24.66575 \\
\hline \multirow{2}{*}{$\Delta$ Biomass } & \multirow{2}{*}{ VAR(1) } & --- & -27.48262 & -27.62640 & -27.75147 \\
\hline & & 1986 & -27.60528 & -27.97342 & -28.13746 \\
\hline \multirow{2}{*}{$\Delta$ Electricity } & \multirow[t]{2}{*}{ VAR(1) } & -- & -29.40741 & -29.73422 & -29.90792 \\
\hline & & 1986 & -29.63911 & -29.94140 & -30.23025 \\
\hline
\end{tabular}

Table 5: Policy functions for Final Energy Consumption

\begin{tabular}{|c|c|c|c|c|c|c|c|}
\hline & $\begin{array}{c}\text { Dummy } \\
1986\end{array}$ & $\begin{array}{c}\text { Dummy } \\
1999\end{array}$ & Constant & Trend & $\Delta y(-1)$ & $\Delta \mathrm{l}(-1)$ & $\Delta \mathrm{ip}(-1)$ \\
\hline$\Delta$ Aggregate Energy & $\begin{array}{c}0.00960 \\
(0.55135) \\
\end{array}$ & $\begin{array}{c}0.00673 \\
(0.44913)\end{array}$ & $\begin{array}{c}0.03018 \\
(1.98963)^{* *}\end{array}$ & $\begin{array}{c}-0.00636 \\
(-0.43495)\end{array}$ & $\begin{array}{c}0.55936 \\
(1.79319)^{* *}\end{array}$ & $\begin{array}{c}-0.06244 \\
(-0.26068)\end{array}$ & $\begin{array}{c}0.04271 \\
(0.56001)\end{array}$ \\
\hline$\Delta$ Petroleum & $\begin{array}{c}0.01888 \\
(1.11089) \\
\end{array}$ & & $\begin{array}{c}0.01659 \\
(1.14929)\end{array}$ & $\begin{array}{c}-0.00099 \\
(-0.91642)\end{array}$ & $\begin{array}{c}0.22170 \\
(0.60207)\end{array}$ & $\begin{array}{c}-0.14668 \\
(-0.59658)\end{array}$ & $\begin{array}{c}0.16301 \\
(1.61113)^{*}\end{array}$ \\
\hline$\Delta$ Coal & $\begin{array}{c}0.13606 \\
(0.73553) \\
\end{array}$ & & $\begin{array}{c}0.19321 \\
(1.27456) \\
\end{array}$ & $\begin{array}{c}-0.01683 \\
(-1.27456) \\
\end{array}$ & $\begin{array}{c}2.20795 \\
(0.58274) \\
\end{array}$ & $\begin{array}{c}-2.19353 \\
(-0.68222) \\
\end{array}$ & $\begin{array}{c}-1.55889 \\
(-1.46612)^{*} \\
\end{array}$ \\
\hline$\Delta$ Gas & $\begin{array}{c}-0.16230 \\
(-0.51372)\end{array}$ & $\begin{array}{c}0.20824 \\
(0.66956) \\
\end{array}$ & $\begin{array}{c}-0.04888 \\
(-0.18256) \\
\end{array}$ & $\begin{array}{c}0.01093 \\
(0.41013) \\
\end{array}$ & $\begin{array}{c}-0.89479 \\
(-0.17040) \\
\end{array}$ & $\begin{array}{c}2.57325 \\
(0.59707) \\
\end{array}$ & $\begin{array}{c}1.31234 \\
(0.93361) \\
\end{array}$ \\
\hline$\Delta$ Biomass & $\begin{array}{c}0.01496 \\
(0.37448) \\
\end{array}$ & & $\begin{array}{c}0.01614 \\
(0.45760) \\
\end{array}$ & $\begin{array}{c}-0.00123 \\
(-0.46091) \\
\end{array}$ & $\begin{array}{c}1.18250 \\
(1.42479)^{*} \\
\end{array}$ & $\begin{array}{c}-0.46663 \\
(-0.74692) \\
\end{array}$ & $\begin{array}{c}-0.46663 \\
(-2.06714)^{* *} \\
\end{array}$ \\
\hline$\Delta$ Electricity & $\begin{array}{c}0.00003 \\
(-0.00170)\end{array}$ & & $\begin{array}{c}0.04638 \\
(2.82961)^{* *}\end{array}$ & $\begin{array}{c}-0.00059 \\
(-0.57633)\end{array}$ & $\begin{array}{c}-0.21950 \\
(-0.52895)\end{array}$ & $\begin{array}{c}0.24322 \\
(0.85491)\end{array}$ & $\begin{array}{c}0.09307 \\
(0.97690)\end{array}$ \\
\hline
\end{tabular}

Note: t-statistics in parenthesis.

*significant at $10 \%$ level; ** significant at 5\% level. 
Table 6: Long-term Accumulated Elasticities with Respect to Energy Consumption

\begin{tabular}{|c|c|c|c|}
\hline & Private investment & Employment & Output \\
\hline $\begin{array}{l}\text { Aggregate energy consumption } \\
\text { Central case } \\
\text { Range of variation } \\
\end{array}$ & $\begin{array}{c}2.33517 \\
{[-0.69657 ; 2.33517]}\end{array}$ & $\begin{array}{c}0.48084 \\
{[0.11040 ; 0.48085]}\end{array}$ & $\begin{array}{c}0.97402 \\
{[0.12443 ; 0.97402]}\end{array}$ \\
\hline $\begin{array}{r}\text { Central case } \\
\text { Range of variation } \\
\end{array}$ & $\begin{array}{c}1.00693 \\
{[-0.35445 ; 0.34628]}\end{array}$ & $\begin{array}{c}0.31714 \\
{[0.002048 ; 0.317143]}\end{array}$ & $\begin{array}{c}0.40249 \\
{[-0.16773 ; 0.40249]}\end{array}$ \\
\hline $\begin{array}{r}\text { Central case } \\
\text { Range of variation } \\
\end{array}$ & $\begin{array}{c}-0.58221 \\
{[-0.58221 ; 0.21112]}\end{array}$ & $\begin{array}{c}-0.00526 \\
{[-0.01127 ; 0.022616]}\end{array}$ & $\begin{array}{c}0.01089 \\
{[0.00298 ; 0.10893]}\end{array}$ \\
\hline $\begin{array}{r}\text { Central case } \\
\text { Range of variation } \\
\end{array}$ & $\begin{array}{c}0.13156 \\
{[0.06302 ; 0.13156]}\end{array}$ & $\begin{array}{c}0.01750 \\
{[0.01044 ; 0.017503]}\end{array}$ & $\begin{array}{c}0.043744 \\
{[0.02770 ; 0.04374]}\end{array}$ \\
\hline $\begin{array}{r}\text { Central case } \\
\text { Range of variation } \\
\end{array}$ & $\begin{array}{c}0.99149 \\
{[0.41024 ; 1.12882]}\end{array}$ & $\begin{array}{c}0.03151 \\
{[-0.05781 ; 0.28106]}\end{array}$ & $\begin{array}{c}0.23780 \\
{[0.07829 ; 0.29346]} \\
\end{array}$ \\
\hline $\begin{array}{r}\text { Central case } \\
\text { Range of variation }\end{array}$ & $\begin{array}{c}1.11494 \\
{[-1.21347 ; 1.11494]}\end{array}$ & $\begin{array}{c}0.43736 \\
{[0.05945 ; 0.43736]}\end{array}$ & $\begin{array}{c}0.65733 \\
{[-0.04243 ; 0.65733]}\end{array}$ \\
\hline
\end{tabular}

Note: Central case refers to the central Choleski orthogonalization assumption . The range of variation refers to all possible values under the Choleski decomposition approach and should not be understood or interpreted as a confidence intervals.

Table 7: The Economic Impact of Final Energy Consumption

\begin{tabular}{|c|c|c|c|c|c|c|}
\hline & \multicolumn{2}{|c|}{ Private Investment } & \multicolumn{2}{|c|}{ Employment } & \multicolumn{2}{|c|}{ Output } \\
\hline & Elasticity & Marginal Product & Elasticity & Jobs Created & Elasticity & Marginal Product \\
\hline Aggregate Energy & 2.34 & 3.55 & 0.48 & 0.00827 & 0.97 & 6.34 \\
\hline Petroleum & 1.01 & 2.36 & 0.32 & 0.00844 & 0.40 & 4.04 \\
\hline Coal & -0.58 & -4.27 & -0.01 & -0.00418 & 0.01 & 3.33 \\
\hline Gas & 0.13 & 3.06 & 0.02 & 0.00440 & 0.04 & 4.26 \\
\hline Biomass & 0.99 & 22.71 & 0.03 & 0.00830 & 0.24 & 23.34 \\
\hline Electricity & 1.12 & 7.90 & 0.44 & 0.03483 & 0.66 & 19.95 \\
\hline
\end{tabular}

Note: Marginal products measure the long-term permanent effects in thousands of Euros of a permanent increase of one ton of oil equivalent in the energy variable considered. 
Table 8: Carbon Dioxide Emission Factors for Various Fossil Fuels

\begin{tabular}{|c|c|c|c|c|c|c|}
\hline Fuel & $\begin{array}{c}\text { Conversion } \\
\text { factor } \\
\text { (TJ/Unit) }\end{array}$ & $\begin{array}{c}\text { Carbon } \\
\text { Emission } \\
\text { Factor } \\
\text { (tC/TJ) }\end{array}$ & $\begin{array}{l}\text { Carbon } \\
\text { Content }\end{array}$ & $\begin{array}{c}\text { Oxidation } \\
\text { Factor }\end{array}$ & $\begin{array}{c}\text { Ratio } \mathrm{CO}_{2}: \mathrm{C} \\
\left(\mathrm{CO}_{2}-44 ; \mathrm{C}-\right. \\
12)\end{array}$ & $\begin{array}{c}\text { Carbon Dioxide } \\
\text { Emission Factor } \\
\left(\mathrm{t} \mathrm{CO}_{2}\right)\end{array}$ \\
\hline Aggregate Energy & 0.041868 & & & & & 3.3098 \\
\hline Petroleum & 0.041868 & 20.0 & 0.8374 & 0.990 & 3.6667 & 3.0396 \\
\hline Anthracite (Coal) & 0.041868 & 26.8 & 1.0509 & 0.980 & 3.6667 & 4.0319 \\
\hline Natural Gas & 0.041868 & 15.3 & 0.6406 & 0.995 & 3.6667 & 2.3371 \\
\hline Biomass & 0.041868 & 29.9 & 1.2519 & 1.000 & 3.6667 & 4.5901 \\
\hline Electricity $^{1}$ & & & & & & 5.2191 \\
\hline Anthracite (Coal) & 0.041868 & 26.8 & 1.0509 & 0.980 & 3.6667 & 3.7762 \\
\hline Diesel & 0.041868 & 20.2 & 0.8457 & 0.990 & 3.6667 & 3.0700 \\
\hline Fuel Oil & 0.041868 & 21.1 & 0.8834 & 0.990 & 3.6667 & 3.2068 \\
\hline Natural Gas & 0.041868 & 15.3 & 0.6406 & 0.995 & 3.6667 & 2.3371 \\
\hline
\end{tabular}

Source: Intergovernmental Panel for Climate Change (2006)

Table 9: The Economic Impact of Reducing Carbon Dioxide Emissions from Fossil Fuel Combustion

\begin{tabular}{|c|c|c|c|c|c|c|}
\hline & \multirow[b]{2}{*}{$\begin{array}{c}\text { Emission } \\
\text { Factor }\end{array}$} & \multicolumn{2}{|c|}{ Private Investment } & \multirow{2}{*}{\begin{tabular}{|c|} 
Employment \\
$\begin{array}{c}\text { Jobs lost for each ton of } \\
\text { carbon dioxide } \\
\text { abatement }\end{array}$ \\
\end{tabular}} & \multicolumn{2}{|c|}{ Output } \\
\hline & & $\begin{array}{c}\text { Marginal } \\
\text { Product }\end{array}$ & $\begin{array}{c}\text { Cost per Ton } \\
\text { of Carbon } \\
\text { Dioxide }\end{array}$ & & $\begin{array}{c}\text { Marginal } \\
\text { Product }\end{array}$ & $\begin{array}{c}\text { Cost per Ton } \\
\text { of Carbon } \\
\text { Dioxide }\end{array}$ \\
\hline Aggregate Energy & 3.31 & 3.55 & 53.55 & 0.0025 & 6.34 & 95.74 \\
\hline Petroleum & 3.04 & 2.36 & 38.83 & 0.0028 & 4.04 & 66.52 \\
\hline Coal & 4.04 & -4.27 & -52.90 & -0.0010 & 3.33 & 45.62 \\
\hline Gas & 2.34 & 3.06 & 91.07 & 0.0042 & 4.26 & 91.07 \\
\hline Biomass & 4.59 & 22.71 & 247.32 & 0.0018 & 23.34 & 254.23 \\
\hline Electricity & 5.22 & 7.90 & 75.64 & 0.0067 & 19.95 & 191.13 \\
\hline
\end{tabular}

Note: Marginal products measure the long-term permanent effects in thousands of Euros of a permanent increase of one ton of oil equivalent in the energy variable considered. Cost per Ton of Carbon Dioxide is measured in Euros per year 
Table 10: Diminishing Marginal Product and Marginal Abatement Costs

\begin{tabular}{|c|c|c|c|c|c|c|}
\hline & \multicolumn{6}{|c|}{ Marginal Effects on GDP } \\
\hline & Petroleum & Coal & Gas & Biomass & Electricity & Total \\
\hline 1993-2003 & 4044.00 & 2162.10 & 7310.91 & 23339.33 & 19950.18 & 6337.71 \\
\hline 1994-2003 & 4049.60 & 2296.10 & 6869.24 & 23679.59 & 19787.96 & 6334.53 \\
\hline 1995-2003 & 4049.30 & 2479.60 & 6372.99 & 24016.42 & 19637.63 & 6323.67 \\
\hline 1996-2003 & 4037.80 & 2678.40 & 5847.87 & 24316.68 & 19454.88 & 6292.31 \\
\hline 1997-2003 & 4033.80 & 3000.60 & 5289.74 & 24662.90 & 19266.79 & 6266.33 \\
\hline 1998-2003 & 4033.00 & 3332.20 & 4722.15 & 24993.91 & 19053.70 & 6230.00 \\
\hline 1999-2003 & 4038.80 & 3678.90 & 4256.55 & 25235.48 & 18799.61 & 6192.81 \\
\hline $2000-2003$ & 4022.90 & 4104.50 & 3900.36 & 25393.69 & 18540.34 & 6136.05 \\
\hline $2001-2003$ & 4016.00 & 5972.10 & 3701.32 & 25374.57 & 18260.65 & 6116.94 \\
\hline $2002-2003$ & 4008.90 & 6828.60 & 3545.17 & 25384.82 & 17910.53 & 6072.42 \\
\hline \multirow[t]{3}{*}{2003} & 4002.70 & 7680.10 & 3403.48 & 24870.86 & 17458.74 & 6011.10 \\
\hline & \multicolumn{6}{|c|}{ Marginal Abatement Costs } \\
\hline & Petroleum & Coal & Gas & Biomass & Electricity & Total \\
\hline 1993-2003 & 66.52 & 26.81 & 156.41 & 254.23 & 191.13 & 95.74 \\
\hline 1994-2003 & 66.61 & 28.47 & 146.96 & 257.94 & 189.57 & 95.69 \\
\hline $1995-2003$ & 66.61 & 30.75 & 136.35 & 261.61 & 188.13 & 95.53 \\
\hline $1996-2003$ & 66.42 & 33.21 & 125.11 & 264.88 & 186.38 & 95.06 \\
\hline $1997-2003$ & 66.35 & 37.21 & 113.17 & 268.65 & 184.58 & 94.66 \\
\hline 1998-2003 & 66.34 & 41.32 & 101.03 & 272.26 & 182.54 & 94.11 \\
\hline 1999-2003 & 66.44 & 45.62 & 91.07 & 274.89 & 180.10 & 93.55 \\
\hline 2000-2003 & 66.17 & 50.90 & 83.45 & 276.61 & 177.62 & 92.70 \\
\hline 2001-2003 & 66.06 & 74.06 & 79.19 & 276.40 & 174.94 & 92.41 \\
\hline $2002-2003$ & 65.94 & 84.68 & 75.85 & 276.52 & 171.59 & 91.73 \\
\hline 2003 & 65.84 & 95.24 & 72.82 & 270.92 & 167.26 & 90.81 \\
\hline
\end{tabular}


Figure 1:

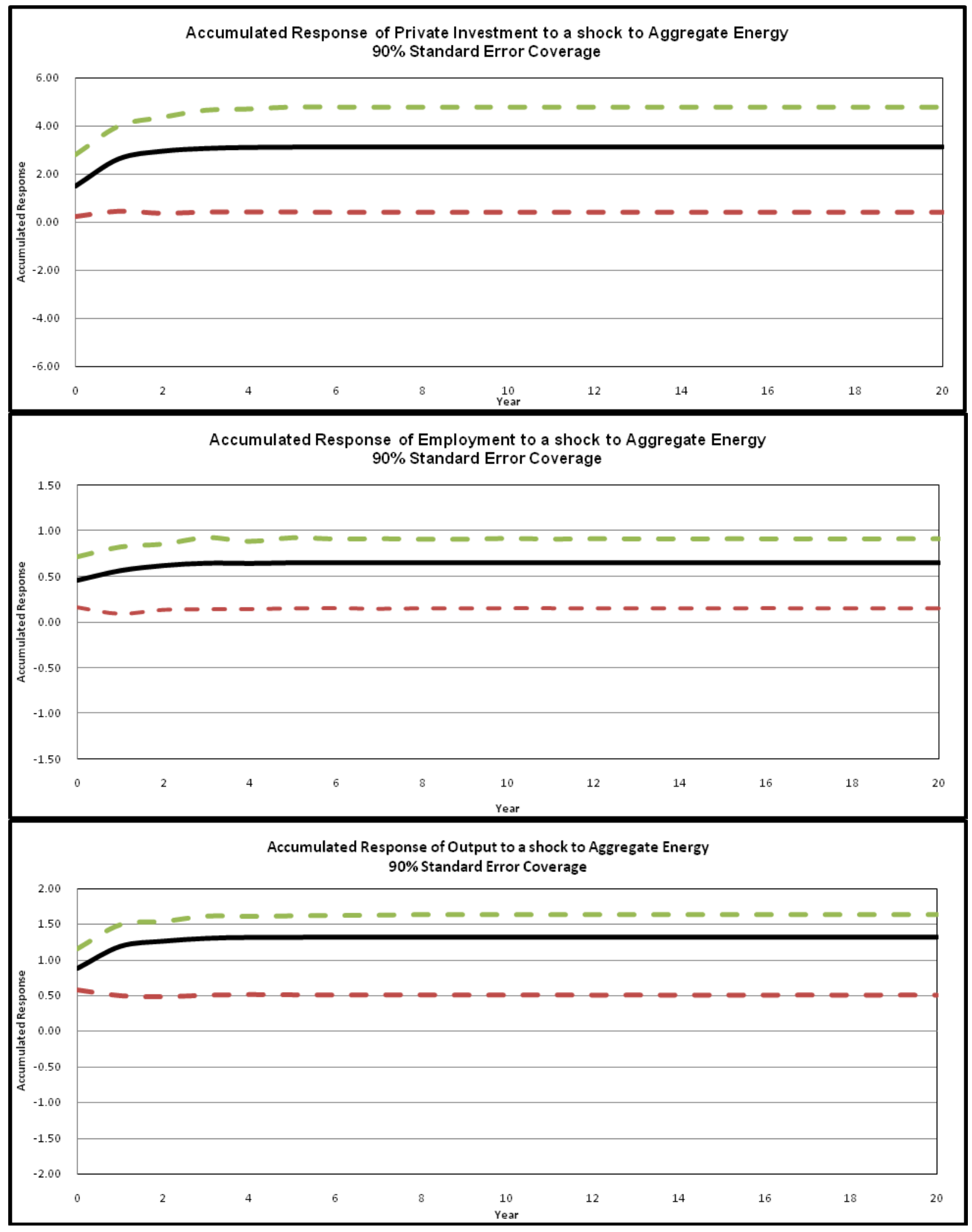


Figure 2:

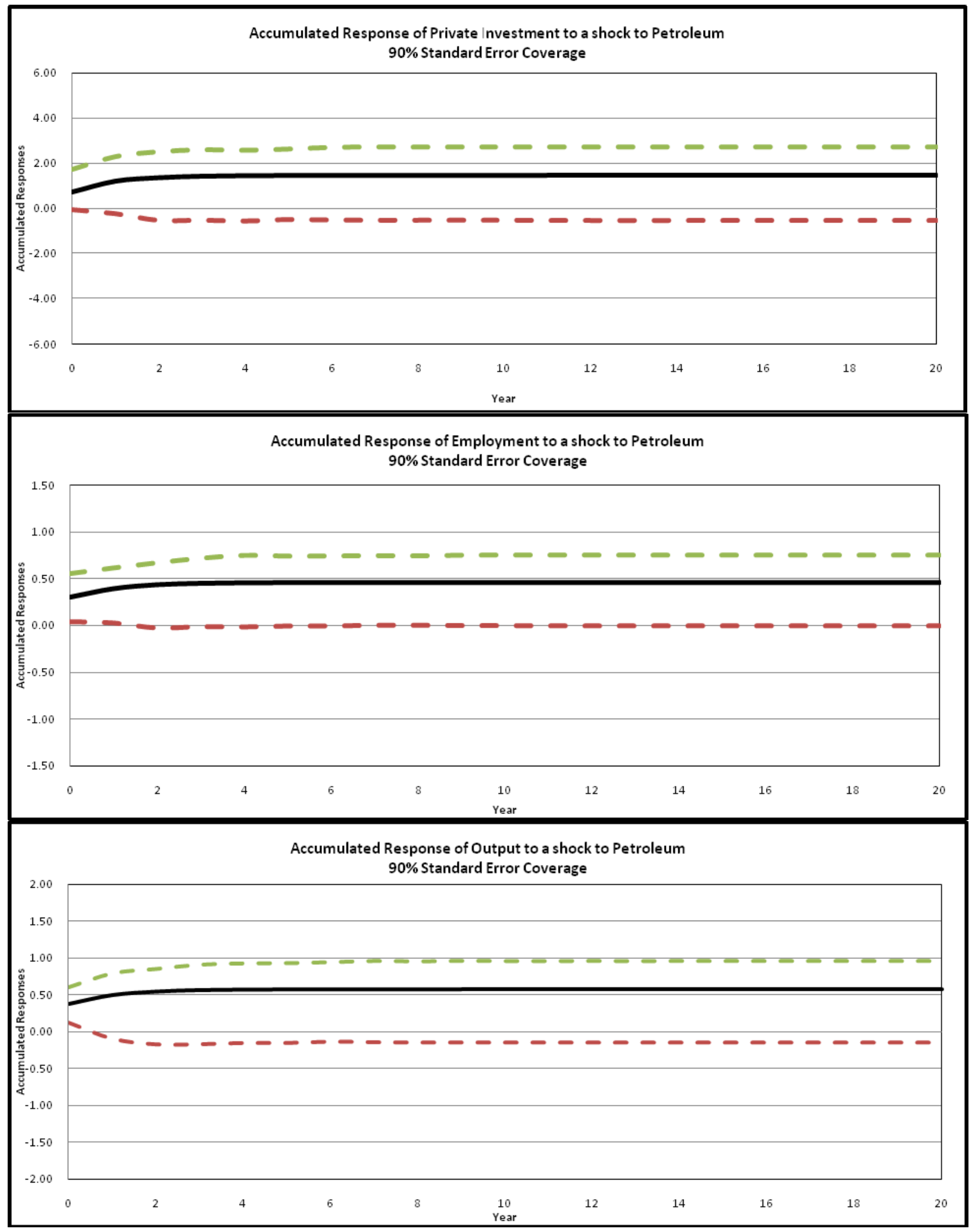


Figure 3:

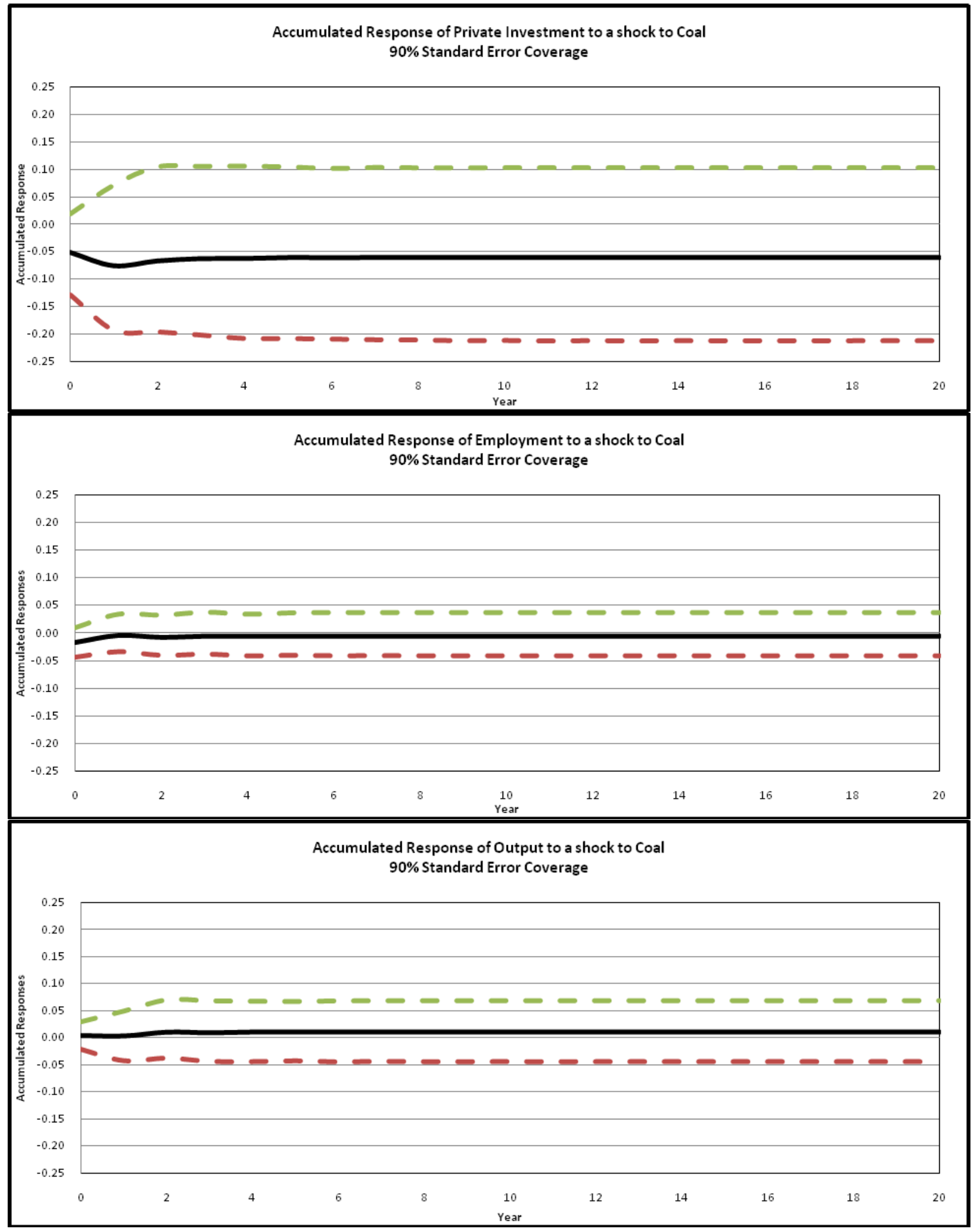


Figure 4:

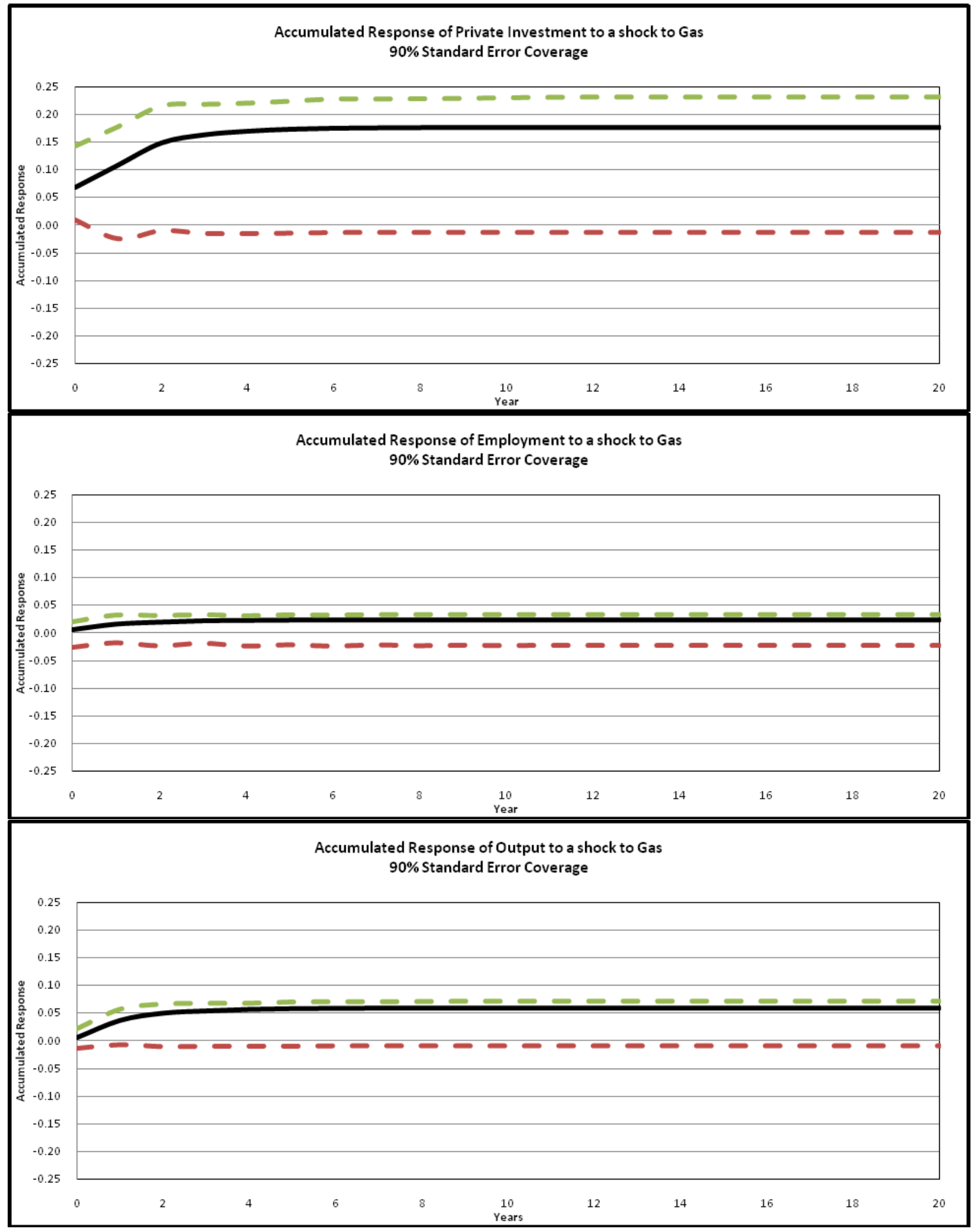


Figure 5:

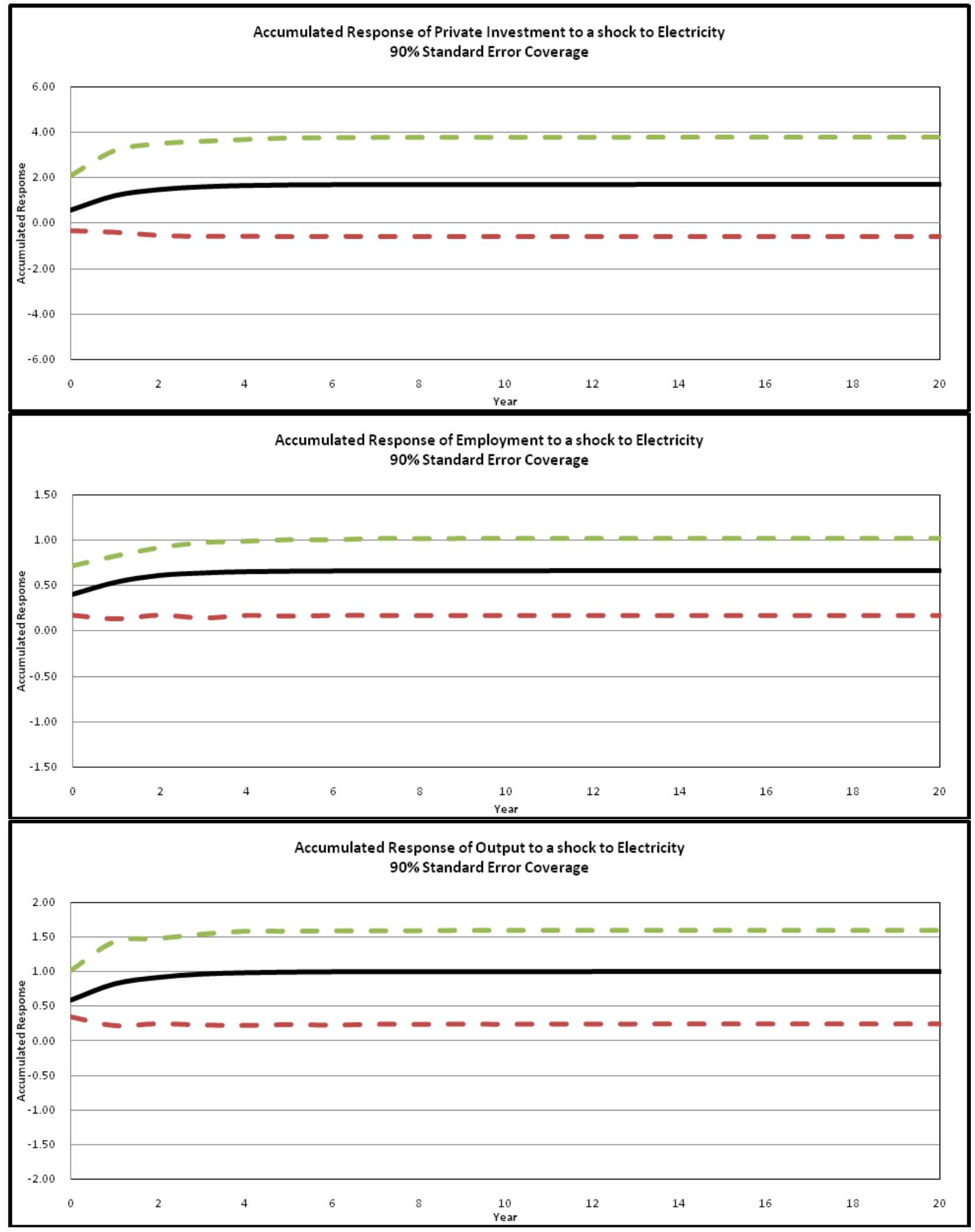


Figure 6:

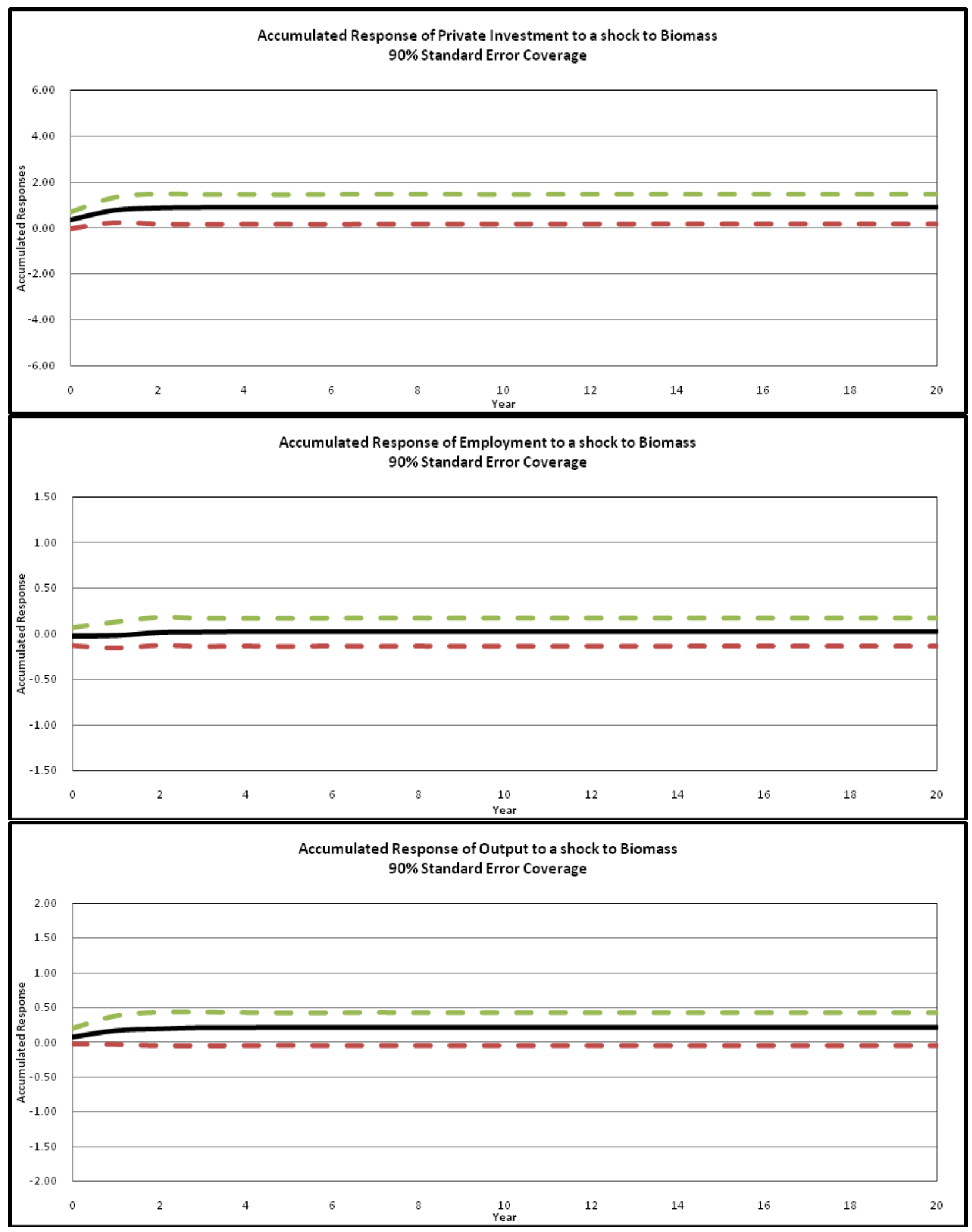

